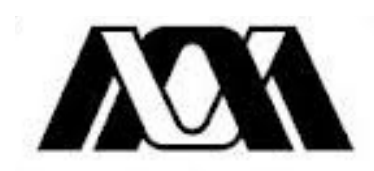

Casa abierta al tiempo

UNIVERSIDAD AUTÓNOMA METROPOLITANA

UNIDAD IZTAPALAPA

DIVISIÓN DE CIENCIAS BIOLÓGICAS Y DE LA SALUD

MAESTRÍA EN BIOLOGÍA DE LA REPRODUCCIÓN ANIMAL

\title{
DETERMINACIÓN DE LA DISTRIBUCIÓN DE BALSAS LIPÍDICAS (LIPID RAFTS) Y CUANTIFICACIÓN DEL COLESTEROL DE LA MEMBRANA DE ESPERMATOZOIDES CRIOPRESERVADOS DE CERDO.
}

\section{TESIS}

PARA OBTENER EL GRADO DE MAESTRA EN BIOLOGÍA DE LA REPRODUCCIÓN ANIMAL PRESENTA:

BIOL.EXP. JANY MARIELA CORONA LEO.

COMITÉ TUTORIAL CODIRECTOR:DR. HUMBERTO GONZÁLEZ MÁRQUEZ CODIRECTORA:DRA. REYNA CARMEN FIERRO PASTRANA ASESORA:DRA. IRMA JIMÉNEZ MORALES MÉXICO D.F. a 26 de Noviembre 2014. 
Co-Director

Dr. Humberto González Márquez

Depto. de Ciencias de la Salud, D.C.B.S. U.A.M.-I.

hgm@xanum.uam.mx

Co-Directora

Dra. Reyna Carmen Fierro Pastrana

Depto. de Ciencias de la Salud, D.C.B.S. U.A.M.-I.

reyna@xanum.uam.mx

Asesora

Dra. Irma Jiménez Morales

Depto. de Ciencias de la Salud, D.C.B.S. U.A.M.-I.

iimi@xanum.uam.mx 


\title{
MIEMBROS DEL JURADO
}

Dra. Irma Jiménez Morales

Depto. de Ciencias de la Salud, D.C.B.S. U.A.M.-I.

¡imi@xanum.uam.mx

Dr. José Antonio Herrera Barragán

Unidad de Manejo y Aprovechamiento Sustentable de Vida Silvestre. DGVS-CR.IN917-MEX/06.

\author{
Depto. De Producción Agrícola y Animal, D.C.B.S. U.A.M.-X \\ mvzjoseherrera@yahoo.com.mx
}

Dra. Edith Arenas Ríos

Depto. Biología de la Reproducción, D.C.B.S. U.A.M.-I.

editharenas2000@yahoo.com.mx

Dr. Marco Allán Pérez Solis

Unidad de Investigación en Biología Reproductiva, Hospital de Gineco-Obstetricia

No. 4. "Luis Castelazo Ayala" IMSS

marco perezsolis@yahoo.es 


\section{AGRADECIMIENTOS}

Este trabajo fue realizado en los Laboratorios de Andrología y de Expresión Génica, del Departamento de Ciencias de la Salud de la Universidad Autónoma Metropolitana Unidad Iztapalapa, bajo la dirección de los Doctores Reyna Carmen Fierro Pastrana y Humberto González Márquez.

CON APOYO FINANCIERO DE:

a) CONACYTproyecto 105961-M.

b) CONACYT-ANUIES-ECOS proyecto M10-A02

c) UNIVERSIDAD AUTÓNOMA METROPOLITANA.

d) La Maestría en Biología de la Reproducción Animal de la Universidad Autónoma Metropolitana conto con apoyo para becas de estudiante en Base al Acuerdo 02/2011 del Rector General.

e) La Maestría en Biología de la Reproducción Animal de la Universidad Autónoma Metropolitana pertenece al Padrón de Posgrados de Excelencia del CONACYT y cuenta con apoyo de becas para estudiantes del mismo Consejo, con número de referencia 003797. 


\section{MIEMBROS DEL JURADO}

El jurado designado por la División de Ciencias Biológicas y de la Salud, Universidad Autónoma Metropolitana Iztapalapa, abajo firmantes, aprobaron la tesis:

Determinación de la distribución de balsas lipídicas (lipid rafts) y cuantificación del colesterol de la membrana de espermatozoides criopreservados de cerdo.

El día 26 de Noviembre 2014

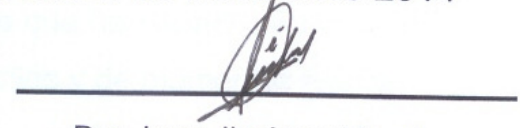

Dra. Irma Jiménez Morales

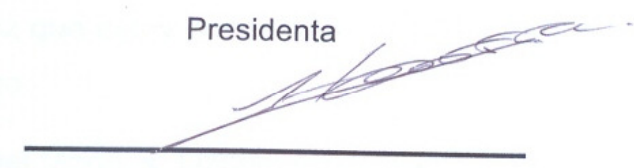

Dr. José Antonio Herrera Barragán

Secretario

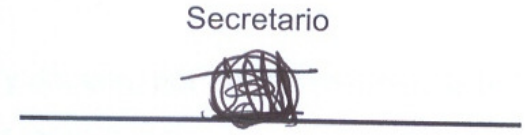

Dra. Edith Arenas Ríos.

Vocal

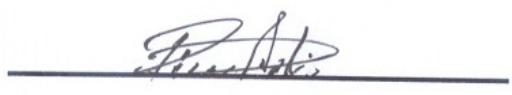

Dr. Marco Allán Pérez Solis

Vocal 


\section{All}

\section{ACTA DE EXAMEN DE GRADO}

UNIVERSIDAD AUTÓNOMA METROPOLITANA

DETERMINACION DE LA

DISTRIBUCION DE BALSAS

LIPIDICAS (LIPID RAFTS) Y

CUANTIFICACION DEL

COLIESTEROL DE LA MEMBRANA DE

ESPERMATOZOIDES

CRIOPRESERVADOS DE CERDO

En México, D.F., se presentaron a las 11:00 horas del día 26 del mes de noviembre del año 2014 en la Unidad Iztapalapa de la Universidad Autónoma Metropolitana, los suscritos miembros del jurado:

DRA. IRMA JIMENEZ MORALES

DRA. EDITH ARENAS RIOS

DR. MARCO ALAN PEREZ SOLIS

DR. JOSE ANTONIO HERRERA BARRAGAN

Bajo la presidencia de la primera y con carácter de Secretario el último, se reunieron para proceder al Examen de Grado cuya denominación aparece al margen para la obtención del gra

MAESTRA EN BIOLOGIA DE LA REPRODUCCION ANIMAL

DE: JANY MARIELA CORONA LEO

y de acuerdo con el artículo 78 fracción III del Reglamento de Estudios Superiores de la Universidad Autónoma Metropolitana, los miembros del jurado resolvieron:

\section{Apsobar}

Acto continuo, la presidenta del jurado comunicó a la interesada el resultado de la evaluación $y$, en caso aprobatorio, le fue tomada la protesta.

HC JUHO CE AR DE LARA ISASS DIRECTOR DE SISTEMAS ESCOLARES
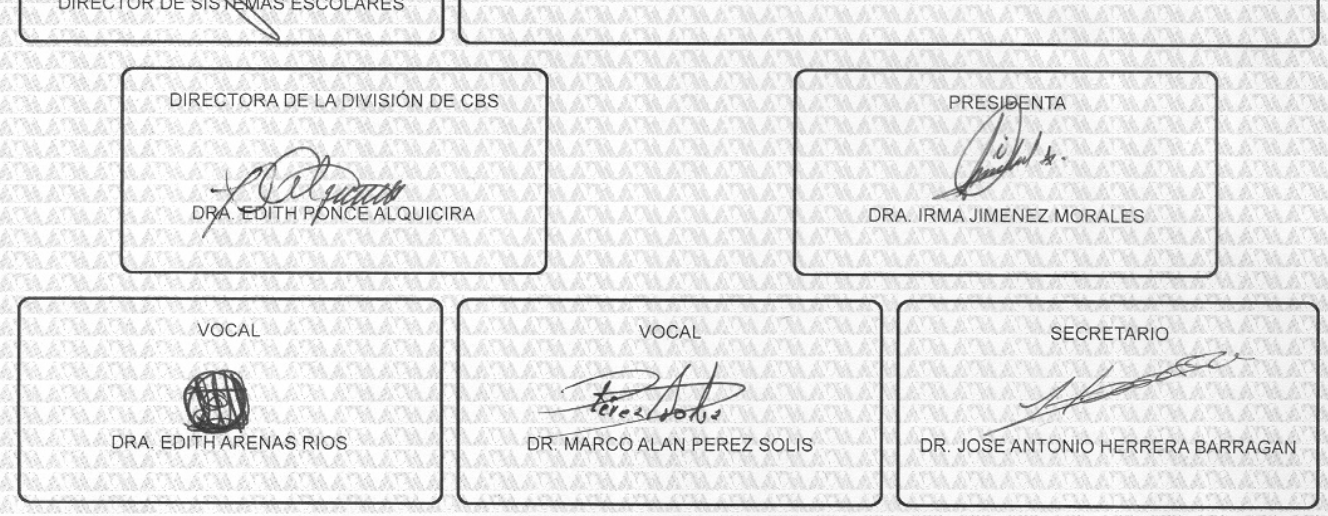


\section{DEDICATORIA}

Este trabajo está dedicado a cada una de las personas que en su momento me supieron brindar su apoyo incondicional de diferentes maneras en esta etapa de mi vida profesional.

A mi pequeño Isaí, tu llegada me hizo recordar lo fuerte que puedo ser, gracias por enseñarme a disfrutar la vida.

A mis padres Celestino Corona y Sandra Leo,que siempre me han protegido, impulsado y que ha respetado cada una de mis decisiones. Gracias papá por enseñarme a ser responsable, por inculcarme a aprender todo lo que pueda y a culminar todos los proyectos que he iniciado.A mi mamá por enseñarme que la vida está llena de momentos difíciles y de momentos bellos.

A mi esposo Luis Antonio Martínez Méndez, gracias miamorpor sostenerme, por estar junto a mi cada vez que estoy por caerme,por todos los momentos felices, por compartir tu vida conmigo.

A mis hermanas Michel Morales, Lizbeth Corona y Evelyn Corona,por ser mis mejores amigas y mis cómplices.A mis cuñados Marco Dorantes y Julio Alvarado por su cariño y apoyo.

A mis sobrinos Yahel y Jocelin,por darme muchos días felices y con cada una de sus ocurrencias, por amar tanto a Isaí.

A mis asesores por el esfuerzo, orientación y apoyo que me brindaron para la realización de este trabajo. 


\section{ÍNDICE}

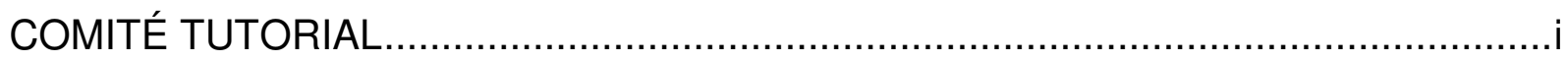

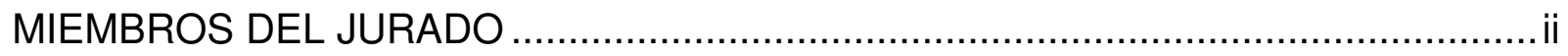

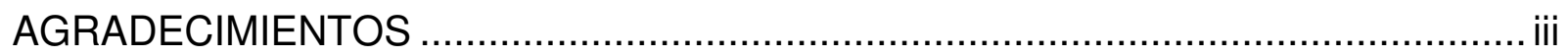

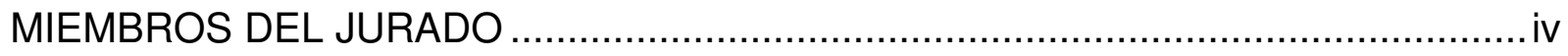

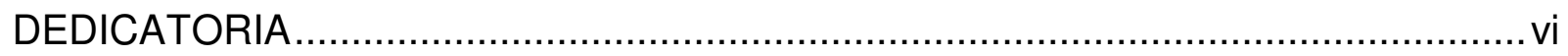

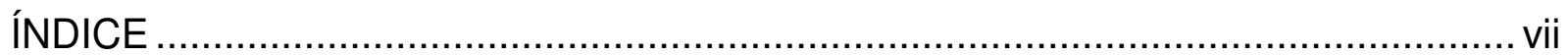

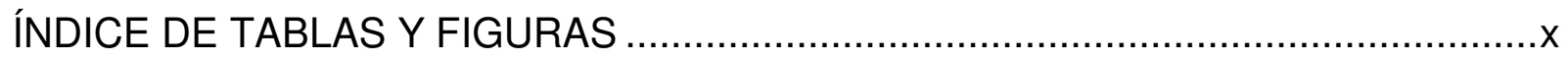

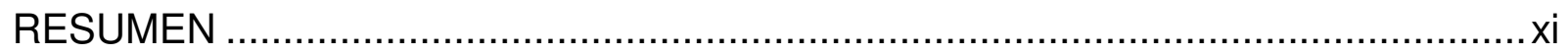

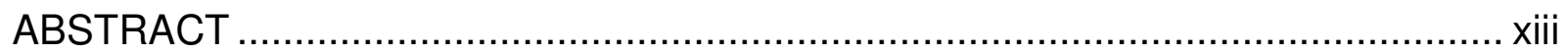

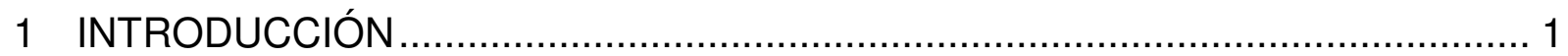

1.1 Membrana plasmática ........................................................................ 1

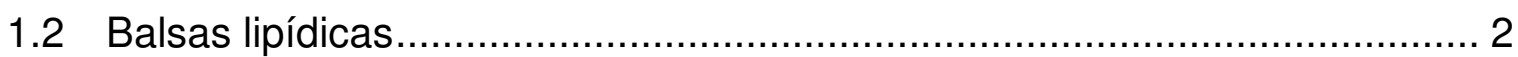

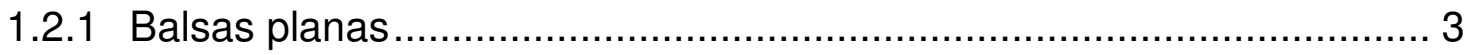

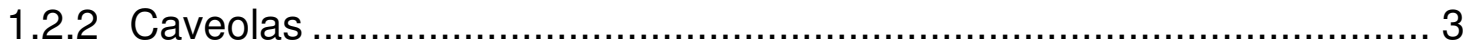

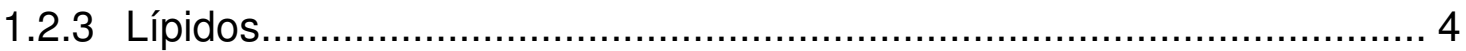

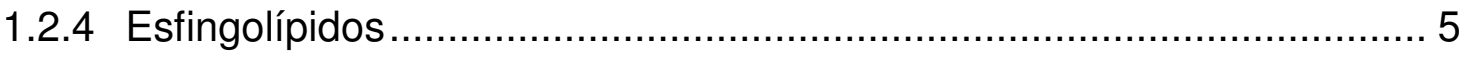

1.2.5 Glicoesfingolípidos ................................................................ 5

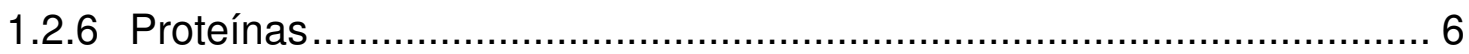

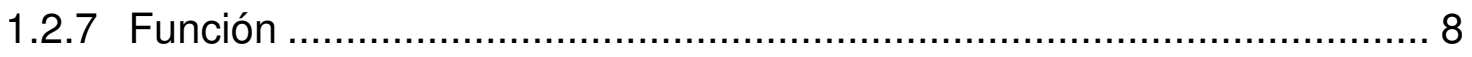

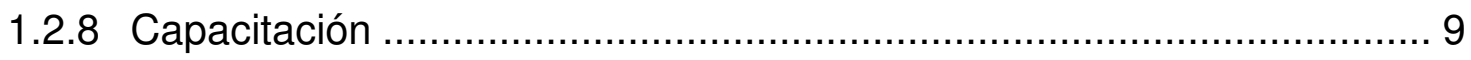

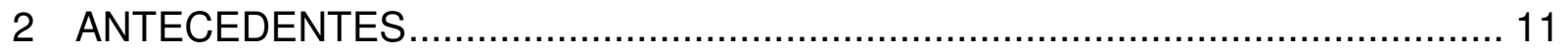

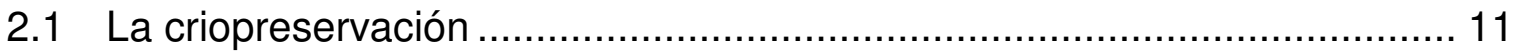

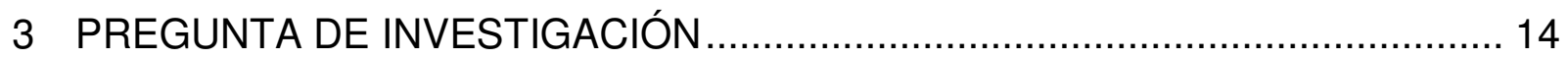




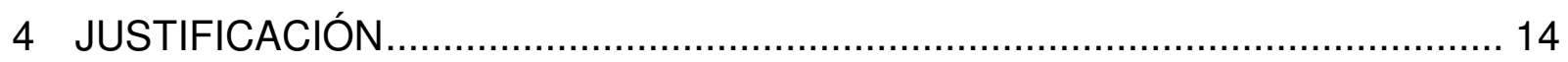

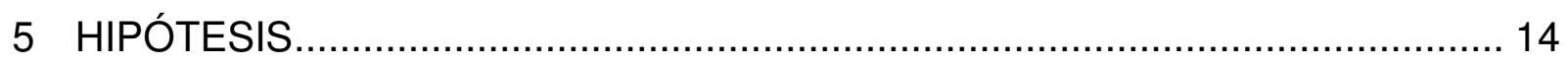

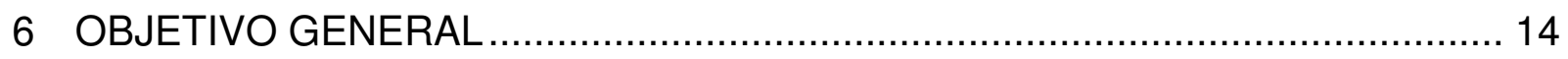

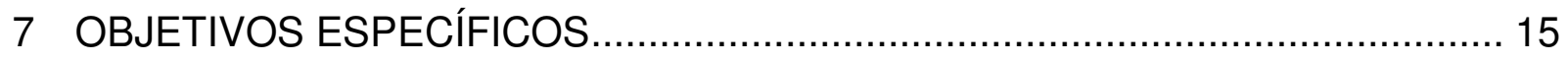

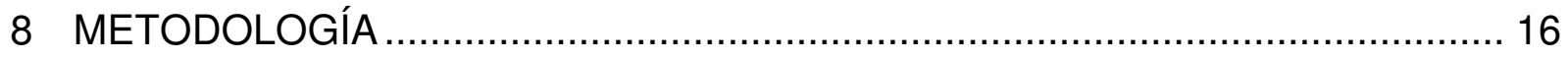

8.1 Lavado de la muestra....................................................................... 16

8.2 Evaluación espermática .................................................................. 16

8.2.1 Evaluación de la movilidad........................................................... 16

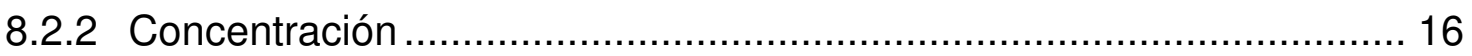

8.2.3 Viabilidad espermática por tinción eosina-nigrosina .......................... 17

8.2.4 Evaluación de formas anormales .................................................. 17

8.2.5 Parámetros de calidad .............................................................. 17

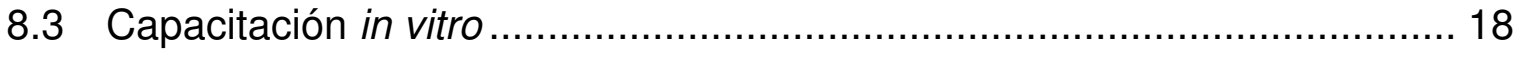

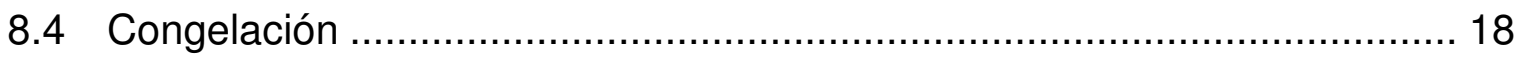

8.4.1 Preparación de la muestra ........................................................... 18

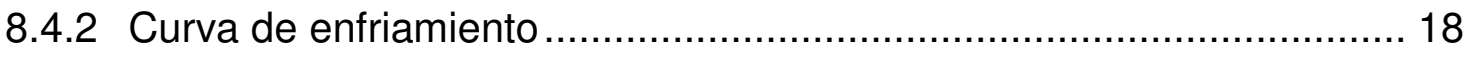

8.4.3 Etapa de crioprotector ............................................................... 19

8.4.4 Empajillado y sellado...................................................................... 19

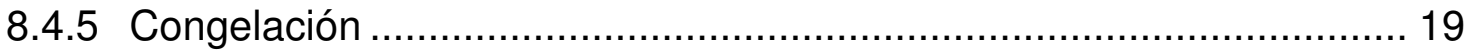

8.4.6 Descongelación............................................................................ 19

8.4.7 Evaluación espermática después de la descongelación ....................... 19

8.5 Distribución de GM1 en la membrana plasmática del espermatozoide de cerdo 20

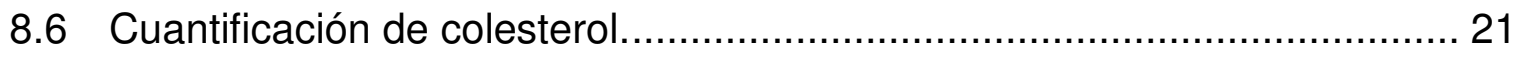




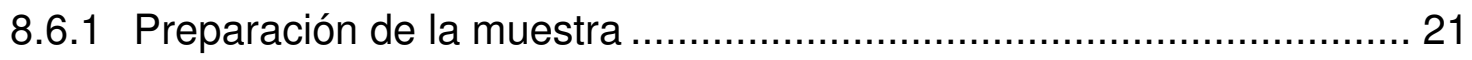

8.6.2 ANÁLISIS ESTADÍSTICO …..................................................... 22

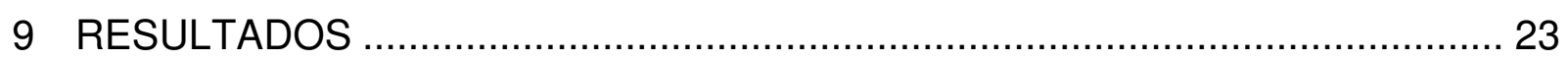

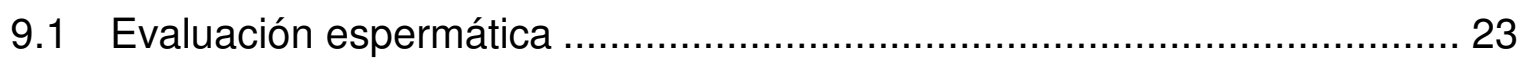

9.2 Evaluación espermática de muestras congeladas/descongeladas. ............ 23

9.3 Distribución del GM1 en la membrana del espermatozoide de cerdo. ........ 23

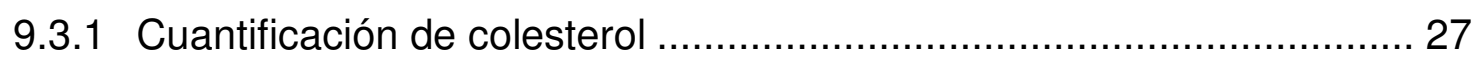

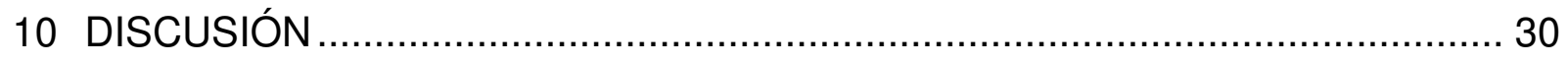

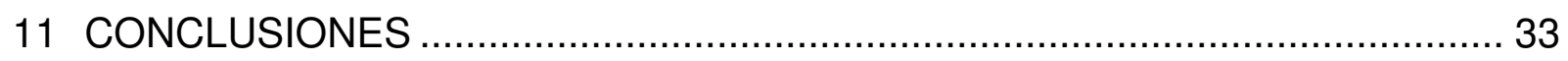

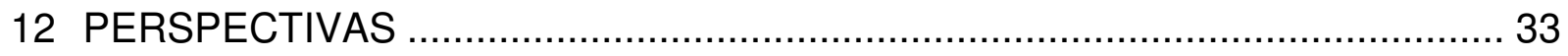

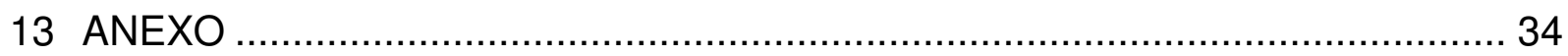

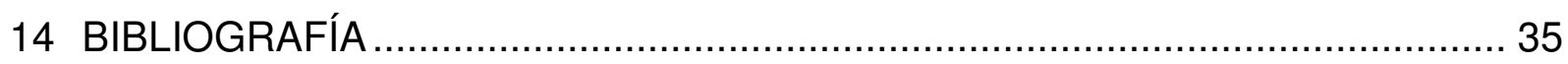




\section{ÍNDICE DE TABLAS Y FIGURAS}

Figura 1. Modelo de mosaico fluido propuesto por Singer y Nicolson 2

Figura 2. Modelo de organización de rafts o caveolas en la membrana plasmática ...4

Figura 3. Heterogeneidad en los mecanismos por los que las proteínas están unidas

a los rafts de lípidos. 7

Figura 4. Curva estándar de colesterol ..........................................................21

Figura 5. Espermatozoide de cerdo a $100 \mathrm{X}$ con patrón de fluorescencia CTX-FITC (a), en campo claro (b)

Figura 6. Espermatozoide de cerdo a 100 X con patrón de fluorescencia CTX-FITC (a), en campo claro (b)

Figura 7. Espermatozoide de cerdo a 100 X con patrón de fluorescencia CTX-FITC (a), en campo claro (b) 24

Figura 8. Espermatozoide de cerdo a 100 X con patrón de fluorescencia CTX-FITC (a), en campo claro (b) . 25

Figura 9. Espermatozoide de cerdo a 100 X con patrón de fluorescencia CTX-FITC (a), en campo claro (b) 25

Tabla 1 : Porcentaje de espermatozoides de cerdo de acuerdo a los patrones de fluorescencia con CTX-FITC, NC (no capacitados), C (capacitados) y C/D (congelados/descongelados)

Figura 10: Patrones de distribución de fluorescencia en espermatozoides.

Tabla 2: Porcentaje de Concentración de colesterol en espermatozoides de cerdo y sobrenadante 28

Figura 11: Concentración de colesterol $(\mu \mathrm{g} / \mathrm{ml})$ en espermatozoides 29 
El proceso de fertilización se caracteriza por una serie de eventos que ocurren tanto en el ovocito como en el espermatozoide, que conducen a la formación del cigoto y finaliza con la formación de un nuevo individuo. Los espermatozoides deben pasar por una serie de eventos moleculares, llamados globalmente capacitación. Este proceso involucra el reordenamiento de lípidos y proteínas, cambios en la permeabilidad de iones y la fosforilación de muchas proteínas, así como, la pérdida de colesterol que provoca la reorganización de las balsas lipídicas. Durante la criopreservación, los espermatozoides disminuyen su capacidad fertilizante, esto se ha relacionado con alteraciones en la membrana plasmática. Los espermatozoides de cerdo presentan, hasta la fecha, la mayor dificultad en preservarse. Este efecto se ha relacionado con la composición lipídica de la membrana plasmática. Solo el $2.5 \%$ de los espermatozoides criopreservados conservan su funcionalidad completa (viabilidad, movilidad, morfología y capacidad de fertilización). El objetivo de este trabajo fue determinar el efecto de la criopreservación sobre la distribución de las balsas lipídicas y sobre la concentración de colesterol en la membranade espermatozoides de cerdo. Para determinar los cambios que se presentan en la distribución de balsas lipídicas de espermatozoides de cerdo sometidos a criopreservación, se utilizó la toxina de cólera unido a fluoresceína (CTX-FTC), como marcador del GM1, glucósido que se encuentra acoplado a las balsas lipídicas, comparándolos con las muestras antes de ser criopreservadas y con espermatozoides que se capacitaron in vitro. Encontrándose 5 patrones de distribución de fluorescencia: A: en flagelo y cabeza, B:intensa en la cabeza pero débil en el flagelo, B1: intensa en la cabeza destacando un anillo semicircular y débil en el flagelo, C:intensa en la cabezay D: en la región post-acrosomal de la cabeza y pieza intermedia del flagelo. Las medias para el porcentaje de los patrones encontrados en espermatozoides no capacitados fueron $\mathrm{A}$ el 88.7, B el 6.3 y $\mathrm{C} 5$; capacitadosin vitro A el 5.5, B el 22.7 y C 71.8; criopreservados A el57.8, B el 13.9, B1 el 1.7, C el 17.1 y D 9.5. Del análisis de concentración de colesterol de la 
membrana plasmática utilizando el kit Amplex Red, se encontraron $183.6 \mu \mathrm{g} / \mathrm{ml}$ en espermatozoides no capacitados,147.6 $\mu \mathrm{g} / \mathrm{ml}$ en espermatozoides capacitados $(p<0.005)$, mientras que en el grupo de criopreservados el colesterol solo se encontró en el medio de congelación $487.9 \mu \mathrm{g} / \mathrm{ml}$. El proceso de criopreservación daña la membrana plasmática de los espermatozoides, provocando la migración de las balsas lipídicas hacia la cabeza del espermatozoide y causa una pérdida importante de colesterol de la membrana plasmática, incrementando enlos espermatozoides capacitados. Sin embargo se requieren otros estudios complementarios tales como análisis de movilidad asistido por computadora, ensayos de reacción acrosomaly cuantificar decolesterol en balsas lipídicas aisladas. 
The process of fertilization is characterized by a series of events that occur in both the oocyte and the sperm, which lead to the formation of the zygote and ends with the formation of a new individual. Sperm must undergo a series of molecular events, called capacitation globally. This process involves the reorganization of lipids and proteins, changes in ion permeability and phosphorylation of many proteins and a reorganization of the plasma membrane domains called lipid rafts, cholesterol and loss of plasma membrane not that rafts. During cryopreservation sperm fertilizing capacity decrease there has been linked to alterations in the plasma membrane. Boar sperm have, to date, the greatest difficulty in preserving. This effect has been related to the lipid composition of the plasma membrane. Only $2.5 \%$ of cryopreserved sperm retain their full functionality (viability, motility, morphology and fertilizing capacity). The aim of this study was to determine the effect of cryopreservation on the distribution of lipid rafts and cholesterol concentration in the membrane of boar sperm. To determine the changes that occur in the distribution of lipid rafts of boar spermatozoa undergo cryopreservation, the cholera toxin bound to fluorescein (CTX-FTC), a marker of GM1, glucose that is coupled to the lipid rafts used, comparing the samples before and cryopreserved sperm that were trained in vitro. Finding three fluorescence patterns: A: flagellum and head, B: Fluorescence labeled weak in the head but in the flagellum and $\mathrm{C}$ : fluorescence in the acrosomal region and postacrosomal and absence in the flagellum. Sperm non-capacitatedA $88.7 \%$, B $6.3 \%$ and $C 5 \%$; capacitated A 5.5\%, B 22.7\% and C 71.8\%; cryopreserved A 57.8\%, B 13.9\% and C $17.1 \%$. Analysis of concentration of plasma membrane cholesterol using the Amplex Red kit, $183.6 \mu \mathrm{g} / \mathrm{ml}$ were found in non-capacitated sperm, $147.6 \mu \mathrm{g} / \mathrm{ml}$ in capacitated sperm, while in the cryopreserved group of cholesterol is only found in the middle freezing $487.9 \mu \mathrm{g} / \mathrm{ml}$. The cryopreservation damages the sperm plasma membrane, causing a slight increase in lipid rafts migration towards the sperm head and the loss of plasma membrane cholesterol, increasing the capacitated sperm. More studies are needed that complement our results by determining the difference in mobility using a 
computerized system, which would provide a more objective analysis; RA evaluate training and chlortetracycline and assays with Coomassie to determine whether the value of the position of the lipid rafts, performed here by tracking GM1, correlates with these processes and quantifying cholesterol in isolated lipid rafts, to determine is the proportion that is anchored to them. 


\section{INTRODUCCIÓN}

El proceso de fertilización se caracteriza por una serie de eventos entre el ovocito y el espermatozoide que conducen a la formación del cigoto y finaliza con la formación de un nuevo individuo(Naz y Rajesh 2004).El espermatozoide debe someterse a una serie de cambios bioquímicos y fisiológicos llamado Capacitación, que permite que el espermatozoide se una a la zona pelúciday realice la reacción acrosomal(Cross 2004, Gadella et al. 2008).

En las últimas dos décadas, varios grupos de investigación han reportado que un gran número de eventos moleculares quecorrelacionan con la inducción de la capacitación, son el reordenamiento de lípidos y proteínas, la regulación de la permeabilidad de iones y la fosforilación de muchas proteínas,así como la reorganización de balsas lipídicas resultado de la pérdida de colesterol(Boerke et al. 2008, Visconti et al. 2011).Procesos como la criopreservación, afecta estructuras como la membrana plasmática, integridad del acrosoma y provoca alteraciones en la función mitocondrial en relación con los espermatozoides no capacitados. El 50\% de los espermatozoides criopreservados que sobreviven al proceso de congelacióndescongelación, presentan el fenómeno de criocapacitación, teniendo una vida más corta y poca eficiencia reproductiva (Hernandez et al. 2007, Bailey et al. 2008).

Hasta la fecha, Los espermatozoides de cerdo presentan,la mayor dificultad para preservarse, tanto a $16-18^{\circ} \mathrm{C}$ como congelados. Estas dificultades parecen deberse a características particulares de su membrana plasmática.

\subsection{Membrana plasmática}

La membrana plasmática es un componente celular generado por interacciones de gran complejidad cuya estructura y función no vienen determinadas por el genoma celular (Mouritsen y Zuckermann 2004).La organización de las células eucariotas está determinada en gran medida por sus membranas biológicas, cuyafunción y estructurase basan en las propiedades intrínsecas de loslípidos de 
membrana.Son entidades dinámicas y fluidas ya que la mayoría de sus lípidos y proteínas son capaces de moverse en el plano de la membrana, además de sufrir un continuo recambio de sus componentes. Su función principal es servir como un límite físico de naturaleza hidrofóbica entre diferentes compartimentos acuosos(Sonnino y Prinetti 2013).La bicapa lipídica se caracteriza por varias propiedades básicas que son importantes para sus funciones biológicas: la bicapa es una estructura estable, que permite que sus componentes tengan cierto grado de movilidad lateral ycomo consecuencia, los componentes se pueden organizar creando áreas (dominios) altamente diferenciadas en composición y arquitectura(Prinetti et al. 2009).

\subsection{Balsas lipídicas}

El modelo de mosaico fluido de Singer y Nicolson, ha sido la base para entender la estructura de las membranas celulares. Describe como los fosfolípidos de la membrana se ordenan en una bicapa formando una matriz fluida, donde se encuentran proteínas periféricas e integrales, unidas a la doble capa de lípidos, pero distribuidas de forma aleatoria. Esta distribución permite que los lípidos y las proteínas tengan movimiento lateral y de rotación.

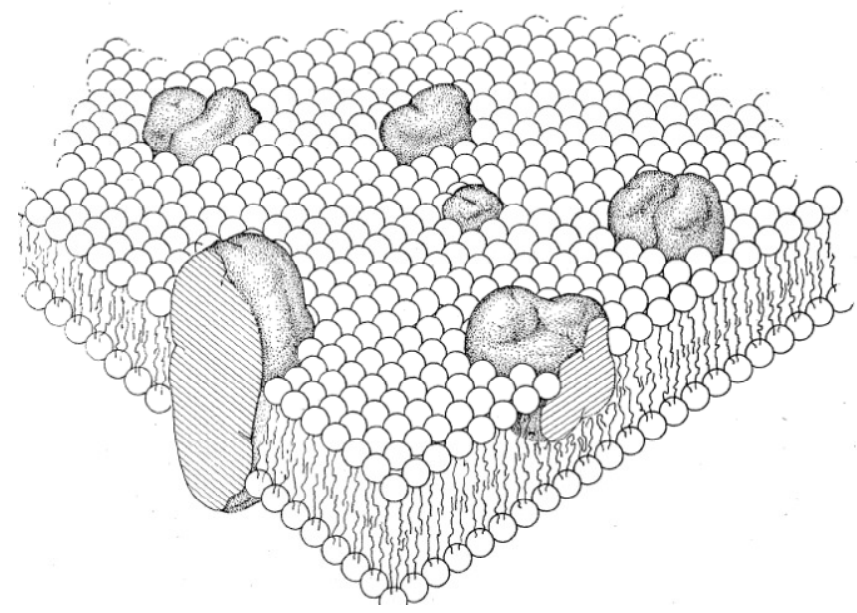

Figura 1 .Modelo de mosaico fluido propuesto por Singer y Nicolson(Singer y Nicolson 1972)

El modelo de mosaico fluido ha ganado complejidad con el postulado de la existencia de dominios o regiones en las membranas biológicas (Colas et al. 2012). 
El origen de la hipótesis de microdominios de membrana o balsas lipídicas (lipid rafts) se basó en las observaciones de la membrana apical de células epiteliales donde existe una alta concentración de ciertos lípidos (colesterol y glicoesfingolipidos) (Simons y Van Meer 1988) y se formalizó posteriormente por Simon e Ikonen(1997 ). Inicialmente, se definieron como DetergentResistantMembrane(DRMs) por las propiedades que permiten su extracción en presencia de Tritón X-100 al $1 \%$, y a que debido a su baja densidad, flotan en la mitad superior de un gradiente de sacarosa del 5 al $30 \%$ (Pike 2004). Una de las razones por la que ha sido tan difícil demostrar su existencia es que pueden ser pequeñas, pero cuando se activan, se agrupan para formar grandes plataformas, en donde las proteínas que se encuentran en ellas pueden interactuar (Simons y Ehehalt 2002); miden entre 10 y $200 \mathrm{~nm}$, poseen características físicas y químicas que las diferencian del resto de la membrana. Debido a las interacciones entre los componentes de la membrana, pueden formarse varios tipos de subdominios con características y funciones diferentes (Helms y Zurzolo 2004).

\subsubsection{Balsas planas}

Alineadas en el plano de la membrana y su caracterización ha sido muy difícil debido a su tamaño pequeño (10-200 nm) (Pike 2006).

\subsubsection{Caveolas}

Un grupo de rafts llamados caveolas (Figura 2c) se forma por polimerización de caveolinas o de proteínas integrales de membrana relacionadas con las caveolinas (por ejemplo la flotilina) que se unen fuertemente al colesterol (Murata et al. 1995). La caveolina forma homo y hetero-oligómeros de masa molecular elevada, que van desde 200 hasta $600 \mathrm{kDa}$ (Monier et al. 1995, Scheiffele et al. 1998). Aunque las funciones generales de las caveolas todavía no se definen completamente, se cree que están implicadas en el transporte de colesterol (Simons y lkonen 2000), el tráfico de la membrana (Nelson y Rodriguez-Boulan 2004), y la transducción de señales (Ostrom et al. 2004). 


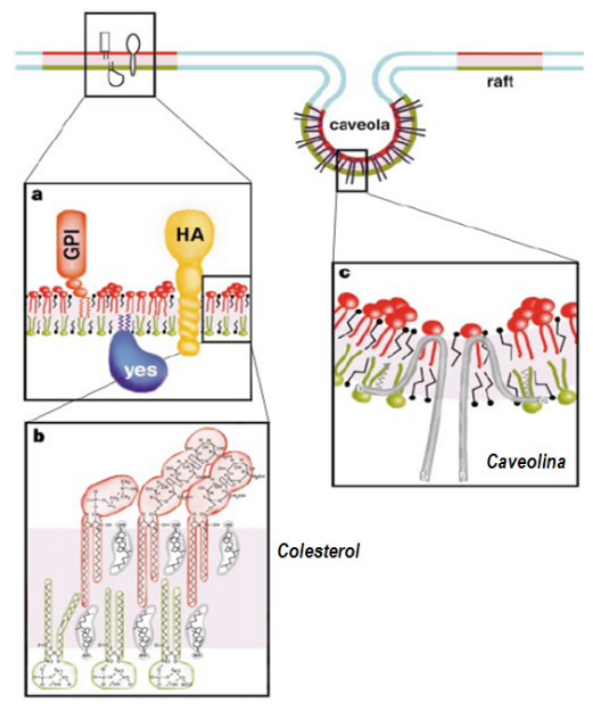

Figura 2. Modelo de organización de rafts o caveolas en la membrana plasmática. Los rafts (rojo-verde) se segregan desde las otras regiones (azules) en la bicapa en la que la fosfatidilcolina insaturada está predominantemente en la cara exoplásmca, que tiene una organización diferente de colesterol intercalado de la que hay en los rafts. a) Los rafts contienen proteínas pegadas a la cara exoplásmica de la bicapa por sus anclas de GPI, las proteínas unidas a la cara citoplásmica por colas de acilo (Se muestra la proteína Yes de la familia de cinasas Src), o proteínas asociadas a través de su dominio transmembranal como las proteínas virales neuraminidasa y hemaglutinina (asociadas con DIGs (Detergent-Insoluble Glycolipids [glicolípidos insolubles en detergentes], en las membranas virales). b) La bicapa lipídica en los rafts es asimétrica con esfingomielina (rojo) y glicoesfongolípidos (rojo) enriquecidos en la cara exoplásmica y glicerolípidos (fosfatidilserina y fosfatidiletanolamina) en la cara citoplásmica (verde). El colesterol (gris), se presenta en ambas caras y llena el espacio bajo los grupos de la cabeza de los esfingolípidos o se extiende entre la cadena acilo grasa en la zona cercana. c. Las caveolas están formadas por moléculas de caveolina ensambladas que hacen una invaginación en la membrana. Las interacciones con los rafts pueden mediarse por la unión de colesterol y por acilación de las cisteínas del extremo C-terminal. Tomado de Simons e Ikonen(2002).

\subsubsection{Lípidos}

El colesterol es un componente esencial de la membrana de las células eucariotas, es el precursor para la síntesis de hormonas esteroides y regulador de múltiples procesos fisiológicos. En la membrana plasmática desempeña numerosas funciones, como mantener su integridad y facilitar la señalización celular.

Una molécula anfipática que se intercala entre los fosfolípidos y glicolípidos en el interior hidrofóbico de la membrana plasmática. Su concentración puede aumentar o disminuir dependiendo del grado de saturación o insaturación de las cadenas de ácidos grasos, evitando que las cadenas se unan, manteniendo así la fluidez de la 
membrana plasmática (Scheiffele et al. 1998, Shadan et al. 2004). El colesterol está implicado en la formación y estabilidad de las balsas lipídicas; su concentración está relacionado con la regulación fisiológica de las balsas lipídicas en las vías de señalización (Zajchowski y Robbins 2002).

Los lípidos anfipáticos como glicerofosfolípidos y esfingolípidos son las compuestos que forman la matriz básica de todas las células en eucariontes (Sonnino y Prinetti 2013). Las concentraciones de fosfoesfingolípidos (esfingomielina) y glicoesfingolípidos es del 15 al $30 \%$ más concentrado en las balsas lipídicas, los esfingolípidos se encuentran expuestos en la bicapa externa de la membrana junto a los glicoesfingolípidos (Simons y Ehehalt 2002).

\subsubsection{Esfingolípidos}

Son lípidos antipáticos que poseen un grupo ceramida, presentan cadenas laterales saturadas y según su grupo hidrofílico, son fosfoesfingolípidos, siendo la esfingomielina la más abundante en mamíferos, representa el 10-12 \% de todos los lípidos de la membrana (Degroote et al. 2004). Los esfingolípidos no sólo participan en varias vías de señalización, también juegan un papel como constituyentes de la membrana, por lo que su diversidad molecular influye en la naturaleza fisicoquímica de las membranas biológicas. Los esfingolípidos participan como reguladores de la función de las proteínas de membrana, pero la especificidad de estas interacciones no se ha explorado ampliamente a nivel molecular hasta la fecha (Ernst y Brugger 2013).

\subsubsection{Glicoesfingolípidos}

Poseen un ácido graso de cadena larga (18-24 carbonos) que interaccionan con la cadenas acílicas de los lípidos de la bicapa interna de la membrana (Van et al. 2008). Entre los glicoesfingolípidos están los gangliósidos, que contienen uno o varios residuos de ácido siálico, se les encuentra principalmente en la cara externa de la membrana, se les ha relacionado con la regulación de diferentes funciones celulares tales como el crecimiento y diferenciación celular, adhesión celular e 
interacción célula-célula (Kalka et al. 2001).En especial, el monosialogangliósido (GM1) tiene una alta afinidad por la subunidad B de la toxina del cólera, y se le ha utilizado para identificar balsas lipídicas(Pike 2004, Blank et al. 2007, Chinnapen et al. 2007). La toxina del cólera (CTB) es una enterotoxina producida por Vibrio choleraey consiste en una subunidad A de $27 \mathrm{kDa}$ y una subunidad B de $14 \mathrm{kDa}$. La subunidad $A$ es esencial para la activación de la adenilatociclasa y la generación de AMPc, pero la captación de CTB está mediada por la subunidad B. La CTB se une a los receptores del GM1 (Blank et al. 2007).

\subsubsection{Proteínas}

La interacción proteína-proteína ha sido considerada el principal factor responsable de la estabilización de los macro y microdominios de la membrana. Las balsas lipídicas tienen la habilidad de reclutar proteínas específicas, tanto transmembranales como unidas a la membrana, ancladas a glicofosfolípidos 0 proteínas modificadas con cadenas acil-lipídicas (Anderson 1998) o combinaciones de las anteriores (Figura 3).

Caveolinas: Son una familia de proteínas integrales de membrana de 20-24 $\mathrm{kDa}(S t a n$ 2005). Funciona como una molécula que ordena complejos proteicos de señalización en la membrana (Sonnino y Prinetti 2009) y son la principal proteína que conforma a las caveolas. Existen 3 isoformas, de las cuales caveolina-1 y 2 se expresan en la mayoría de tipos celulares. La caveolina-1 es esencial para la formación de caveolas y se caracterizó como el primer marcador molecular de estos dominios(Stan 2005, Sonnino y Prinetti 2009). 


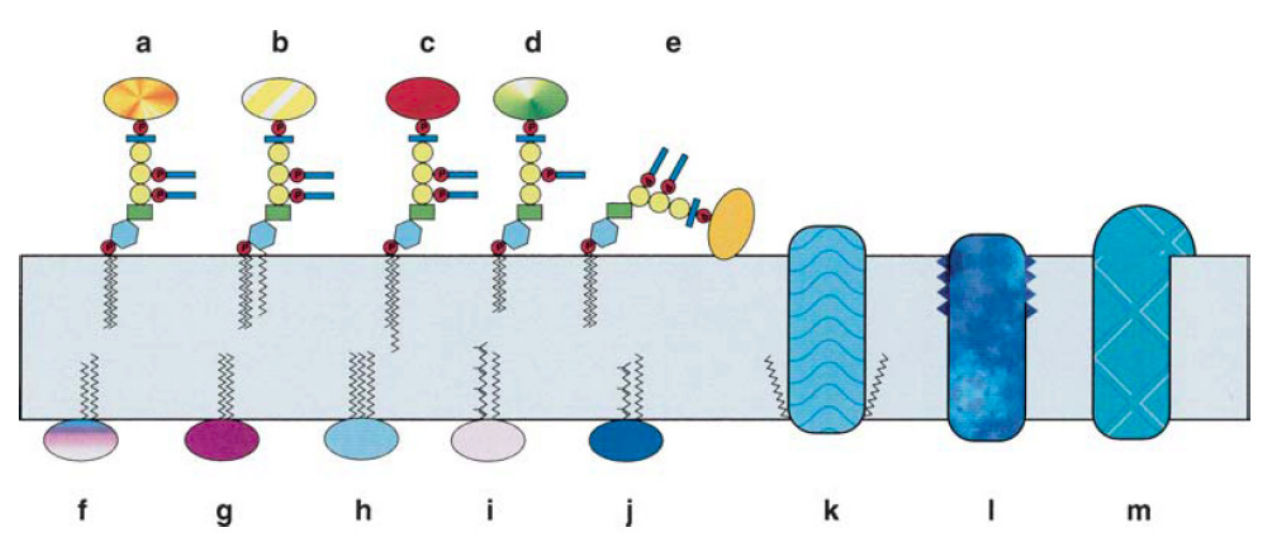

Figura 3. Heterogeneidad en los mecanismos por los que las proteínas están unidas a los rafts de lípidos: a. Proteínas ancladas a GPI en las que el residuo fosfatidilinositol contiene dos grupos acilo $\mathrm{C}_{18: 0}$. $\mathbf{b}$. Proteína anclada a GPI en la que la cabeza de inositol está acetilada. c. Proteínas ancladas a GPI en las que el residuo glicerofosfolípido es reemplazado por una ceramida. d. Proteínas ancladas a GPI en las que las cadenas acilo sn-1 y sn-2 fueron modificadas para contener miristato. e. Proteínas ancladas a GPI en las que una señal extra marcadora de rafts está presente en la parte proteínica de la molécula presente. f. Proteína modificada por la adición de un miristato y un palmitato. g. Proteína modificada por la adición de dos grupos palmitato. $\mathbf{h}$. Proteína modificada por la adición de tres grupos palmitato. i. Proteína modificada por la adición de un grupo geranilgeranil y un palmitato. j. Proteína modificada por la adición de un grupo farnesil y otro palmitato. k. Una proteína transmembranal modificada por la adición de dos grupos palmitato. I. Proteína transmembranal marcada para rafts vía la interacción de los residuos de aminoácidos con la cara exoplásmica de la membrana plasmática. $\mathbf{m}$. proteína transmembranal marcada para rafts por la interacción de su dominio extracelular con constituyentes del raft. La lista no es completa y pueden existir otros ejemplos. Tomado de (Pike 2004).

Flotilinas: Suelen presentarse en compañía de la caveolina, se utilizan como marcadores de balsas lipídicas, no tienen la capacidad de unión a colesterol, se asocian a la membrana por palmitoilación a través de su región $\mathrm{N}$-terminal (Browman et al. 2007).

Proteínas G: Reciben su nombre por la unión a nucleótidos de guanosina. Se presentan como trímeros con las 3 subunidades ( $\alpha, \beta$ y $\gamma$ ) localizadas en la cara interna de la membrana plasmática (Chun et al. 1994).

Familia Src: Son proteínas tirosina quinasa que funcionan como proteínas acopladoras en la transducción de señales(Simons y lkonen 1997 ). 
Proteínas transmembrana: Entre ellas se encuentra el receptor de insulina (RI) (Gustavsson et al. 1999) y receptores acoplados a proteínas G (GPCRs) (Chini y Parenti 2004).

Proteínas ancladas a GPI: Son proteínas unidas a glicosilfosfatidilinositol (GPlanchoredproteins) que se anclan a las balsas gracias a las dos cadenas de ácidos grasos, normalmente saturados, del fosfatidilinositol (Brown y Rose 1992). El CD59, de 18-25 kda, por estar relacionado con la interacción espermatozoideovocito, se ha utilizado para marcar balsas lipídicas.

\subsubsection{Función}

Las balsas lipídicas participan en varios procesos celulares como el control de la adhesión y migración celular, el establecimiento de las sinapsis, la organización del citoesqueleto y en la distribución y tráfico de proteínas en procesos de exo y endocitosis (Simons y Toomre 2000 ) además de procesos patológicos, al ser las regiones de membrana por donde algunos virus (Suomalainen 2002), bacterias (Munro 2003) y toxinas (Kovbasnjuk et al. 2001) atacan a las células.

Por otra parte, las balsas lipídicas funcionan como plataformas de señalización donde se concentra gran parte de proteínas implicadas en ella (Simons y Ikonen 1997 ). Se ha demostrado que las balsas lipídicas se encuentran en células somáticas que están presentes en los espermatozoides de mamíferos, con una morfología diferenciada que se refleja en la superficie de su membrana (Colas et al. 2012). Se sabe que participan en la modulación de aspectos claves de la maduración del espermatozoide y las interacciones del espermatozoide-ovocito (Nixon et al. 2011, Colas et al. 2012).

En los estudios en que se relacionan los espermatozoides de mamíferocon las balsas lipídicas, dos líneas de investigación han predominado: 
1. Estudios sobre las propiedades físicas y bioquímicas de las balsas lipídicas y sobre cómo se relacionan con la capacitación del espermatozoide

2. Estudios sobre cómo las balsas modulan el funcionamientodel espermatozoide.

Sobre estos estudios se ha argumentado que la composición y distribución espacial de las balsas lipídicas pueden funcionar como un indicador del estado de capacitación de los espermatozoides, esta migración en respuesta a la capacitación permite la interacción con los receptores de la zona pelúcida y facilita la activación de las vías de señalización(Nixon et al. 2011).

Los espermatozoides requieren de dos fases de maduración fisiológica con el fin de adquirir la capacidad de fertilizar al ovocito: 1) maduración en el epidídimo, donde hay una modificación a nivel de proteínas y de lípidos que permite la movilidad del espermatozoide. 2) Modificación a nivel de la membrana plasmática y activación en el tracto reproductor femenino, proceso denominado capacitación (Flesch et al. 2001).

\subsubsection{Capacitación}

Un gran número de eventos moleculares ha sido relacionado con la inducción de la capacitación, entre ellos el reordenamiento de lípidos y proteínas en la membrana plasmática. Uno de los más importantes, es el flujo de salida de colesterol, modulado por las secreciones del tracto reproductor femenino, donde hay una alta concentración alta de albúmina;provocando la disminución de colesterol, que a su vez, le da fluidez a la membrana, activandolos canales de calcio y bicarbonato(Vadnaisa y Althousea 2011). El aumento en la concentración de estos iones en el citoplasma de la célula, estimulan a la proteína $\mathrm{G}$ (adenilato-ciclasa) que comienza a producir AMPc a partir de AMP. El incremento en los niveles de AMPc, activa a proteínas cinasas dependientes de AMPc (proteína cinasas A). Estas 
cinasas se activan por fosforilación de residuos de tirosina(Cross 2004). El evento culmina cuando la membrana plasmática y la membrana externa del acrosoma se vuelven más fluidas y adquieren la capacidad de fusionarse una con otra(Gadella et al. 2008). El resultado final de esta remodelación es un espermatozoide con una membrana plasmática adecuada para interaccionar con la zona pelúcida del ovocito y llevar a cabo la reacción acrosomal (Visconti 2009).

Los estudios sobre balsas lipídicas en espermatozoides han comenzado a dar información importante sobre el proceso de capacitación.En la última década las investigaciones han tenido interés en las modificaciones de la función y localización de proteínas en dominios específicos de la membrana, que se dan por la liberación del colesterol en la membrana plasmática durante la capacitación(Miranda et al. 2009).

Las investigaciones siguientes podrían aportar información sobre las modificaciones en la conformación, comportamiento y función de la membrana plasmática de espermatozoides que son sometidos a diferentes procesos como la criopreservación o la exposición a tóxicos. 


\section{ANTECEDENTES}

\subsection{La criopreservación}

Los tratamientos a los que son sometidos los espermatozoides como: la incubación, clasificación por citometría de flujo, la refrigeración o criopreservación, afecta estructuras como la membrana plasmática, lo que da como resultado la muerte celular (Maxwell y Johnson 1999)

La criopreservación es el mantenimiento celular en un estado de animación suspendida que se mantiene a temperaturas criogénicas. Suspendiendo todo proceso químico, biológico y actividad física intracelular y extracelular, por un tiempo indefinido, preservandoel potencial y la viabilidad celular.

La criopreservación de semen es una técnica accesoria para la inseminación artificial, la fertilización in vitro, y en el mejoramiento reproductivo de diferentes especies animales(De Mercado et al. 2010).Durante el proceso seinterrumpe del metabolismo celular por un tiempo determinado, conservando indefinidamente su potencial fertilizante. Este proceso involucra una serie de pasos: refrigeración, crioprotección, congelamiento, almacenamiento y descongelación. El protocolo desarrollado por Westendorf et al. (1975), es el que se utilizan actualmente, con algunas modificaciones con respecto al envasado, a las curvas de enfriamiento, a la fase de adición del crioprotector.

Inicialmente esta técnica fue diseñada para preservar el semen de bovino, pero se ha utilizado en otras especies con algunas modificaciones. En humanos la congelación de semen se utiliza en el tratamiento de la infertilidad humana. En especies de importancia económica, su uso se ha destinado a el mantenimiento e intercambio del germoplasma, almacenamiento a largo plazo que facilita su transporte, programas de mejoramiento genético de especies domésticas para obtener crías más eficientes, el control de la transmisión de patógenos,,conservación 
y preservación de recursos zoogenéticos en especies en peligro de extinción (Eriksson y Rodriguez-Martinez 2000, De Mercado et al. 2010).

La criopreservación de semen, junto con la inseminación artificial, ha sido de las técnicas más desarrolladas y aplicadas en la producción porcina a nivel mundial. El semen criopreservado de cerdo ha estado disponible desde 1975 y a pesar de las ventajas que tiene sobre el semen refrigerado su uso comercial es limitado, debido a la alta susceptibilidad de los espermatozoides al choque frío que afecta su sobrevivencia después de la descongelación.Este efecto se ha relacionado con la composición lipídica de la membrana plasmática. Sin embargo el aumento de la exportación de semen porcino hace necesario la mejora de las técnicas de criopreservación (Waterhouse et al. 2006). Las investigaciones actuales en la criopreservación de semen porcino incluyen diversas estrategias para mejor la calidad de los espermatozoides y aumentar el número de espermatozoides disponibles para la fertilización(Grossfeld et al. 2008).

A pesar de los avances en la metodología, los espermatozoides que son sometidos a criopreservación aún sufren una serie de cambios que comprometen su estructura y capacidad funcional. El efecto que tienen los procesos de congelacióny descongelación en la membrana plasmática se relacionan con la disminución en la movilidad y viabilidad de los espermatozoides. La membrana plasmática de la pieza principal, intermedia y cabeza, son los sitios que sufre más daño durante la fase de congelación-descongelación. Aunque los espermatozoides criopreservados son capaces de fertilizar ovocitos, su esperanza de vida en el tracto reproductor femenino es más corto que el recién eyaculado(Sancho et al. 2007, Vadnaisa y Althousea 2011).

A pesar de las ventajas que tiene el semen congelado, su uso se ha destinado a programas de mejoramiento genético de especies domésticas y a la conservación de recursos zoogenéticos en especies en peligro de extinción y en intercambio internacional de germoplasma(Eriksson y Rodriguez-Martinez 2000). 
A pesar de los avances en la metodología, los espermatozoides que son sometidos a criopreservación se exponen a una serie de cambios que comprometen su estructura y capacidad funcional. El efecto que tiene la congelacióndescongelación es la disminución de la movilidad, viabilidad, integridad de la membrana y estado acrosomal. Además de presentar una subpoblación de espermatozoides en un estado parecido a la capacitación o pre capacitación (criocapacitación) que culmina en una reacción acrosomal espontánea(Bailey et al. 2008). El mecanismo por el cual se produce la criocapacitación aún no se entiende completamente.

En particular los espermatozoides de cerdo son sensibles a los daños por peroxidación debido a su alto contenido de ácidos grasos poliinsaturados, que son sustratos para la generación de especies reactivas de oxigeno (ROS) en la membrana. Las ROS están implicados en la función espermática incluyendo hiperactivación, capacitación y reacción acrosomal. Pero cuando la producción de ROS aumenta se crea un estrés oxidativo. El daño que causa el estrés oxidativo es resultado del desequilibrio entre oxidantes y los mecanismos antioxidantes de los organismos(Hernandez et al. 2007). La acumulación de ROS durante el procesos de criopreservación está asociado con alteraciones en la función mitocondrial, que conducen a una muerte celular programada y con la fragmentación del ADN(Flores et al. 2009).

A pesar de las mejoras realizadas en los últimos años en el desarrollo de la criopreservación, este procedimiento sigue siendo insuficiente para ser aplicada de manera rutinaria en la industria porcina. Solo el $2.5 \%$ de los espermatozoide criopreservados conservan su funcionalidad completa (viabilidad, movilidad, morfología y capacidad de fertilización)(Holt et al. 2005, Vadnaisa y Althousea 2011).En la actualidad, las investigaciones se están enfocando en aquellos aspectos que puedan mejorarla. 


\section{PREGUNTA DE INVESTIGACIÓN}

¿Cuál es el efecto de la criopreservación sobre ladistribución de las balsas lipídicas y concentración de colesterol en la membrana de espermatozoides criopreservados de cerdos?

\section{JUSTIFICACIÓN}

Durante el proceso de congelación-descongelación de los espermatozoides disminuye su capacidad fertilizante, esto se ha relacionado con alteraciones en la membrana plasmática.

La pérdida selectiva del colesterol y los cambios en la distribución de las balsas lipídicas en la membrana plasmática no se han estudiado en espermatozoides criopreservados. Los resultados derivados de este trabajo podrían colaborar en la mejora de los métodos de criopreservación utilizados en la reproducción asistida y la producción animal.

\section{HIPÓTESIS}

Los espermatozoides al ser sometidos a criopreservación, presentarán cambios en la distribución de las balsas lipídicas y en la concentración de colesterol en la membrana plasmática.

\section{OBJETIVO GENERAL}

- Determinar el efecto de la criopreservación sobre la distribución de las balsas lipídicas y concentración de colesterol en la membrana de espermatozoides de cerdo. 


\section{OBJETIVOS ESPECÍFICOS}

- Determinar la calidad espermática de la muestra evaluando concentración, movilidad, viabilidad y anomalías morfológicas.

- Estandarizar la técnica de congelación lenta.

- Determinar mediante microscopia de fluorescencia la distribución de las balsas lipídicas en la membrana de espermatozoides no capacitados (NC) y criopreservados (CP).

- Determinar la concentración del colesterol en la membrana de espermatozoides no capacitados y CP. 


\section{METODOLOGÍA}

El trabajo se realizó con 5eyaculados de sementales (raza Landrace y York), procedentes de la granja de mejoramiento genético "los chotes". Las muestras se trasladaron al laboratorio en un termoa temperatura ambiente y protegidas de la luz.

En el laboratorio se realizó la evaluación de los eyaculados determinando la movilidad, viabilidad, anormalidades morfológicas y concentración espermática. Para los ensayos posteriores se utilizaron las muestras que presentaron los siguientes parámetros $\geq 100 \times 10{ }^{6}$ espermatozoides $/ \mathrm{ml} ; \geq 75 \%$ movilidad; $\geq 80 \%$ viabilidad; $\leq 5$ $\%$ de anormalidadesdescartando las de baja calidad.

\subsection{Lavado de la muestra}

Para la preparación de las muestras seleccionadas se centrifugó a 750 rpm x 4 min,para separar el plasma seminal de la fracciónespermática, se lavó2 veces en PBS (amortiguador de fosfatos). Posteriormente se ajustó la concentración espermática a $5 \times 10^{6}$ espermatozoides/mlpara realizar los ensayos de capacitación, criopreservación, distribución de balsas lipídicas y cuantificación de colesterol.

\subsection{Evaluación espermática}

\subsubsection{Evaluación de la movilidad}

El porcentaje de espermatozoides móviles se realizó colocando una alícuota de $10 \mu \mathrm{L}$ de la muestra del eyaculado, sin diluir sobre un portaobjetos precalentado a $38^{\circ} \mathrm{C}$ y se observó bajo un microscopio de campo claro $(10 \mathrm{X})$. Se estimó el porcentaje de e espermatozoides con movimiento progresivo.

\subsubsection{Concentración}

- Sedeterminó utilizando un hemocitómetro de Neubauer, realizando una dilución $1: 100$ con agua miliQ. Se tomaron $15 \mu \mathrm{L}$ de la dilución para cargar la cámara de Neubauer, se contó el número de espermatozoides bajo un microscopio de 
campo claro 40 X. La concentración de espermatozoides se expresó $10^{6}$ espermatozoides por $\mathrm{ml}(\mathrm{spz} / \mathrm{ml})$.

\subsubsection{Viabilidad espermática por tinción eosina-nigrosina}

Para determinar el porcentaje de espermatozoides vivos y las formas anormales, se utilizó la tinción de eosina/nigrosina. Si el espermatozoide se encuentra muerto, la membrana plasmática permite el paso de la eosina y la cabeza del espermatozoide aparece teñida de color rosa, los espermatozoides vivosno se tiñen, indicando que la membrana plasmática es funcional, ya que no permite el paso de la eosina.

Se colocaron en un portaobjetos precalentado a $38^{\circ} \mathrm{C}, 5 \mu \mathrm{L}$ de la muestra de eyaculado y $5 \mu \mathrm{L}$ de colorante. Una vez mezclados ambos volúmenes, se deslizó un portaobjetos para extender la muestra sobre todo el portaobjetos. Se contaron 200 espermatozoides bajo el microscopio óptico a $40 \mathrm{X}$.

\subsubsection{Evaluación de formas anormales}

De las misma laminilla se determinó el porcentaje de espermatozoides anormales por microscopía óptica. Se contaron 200 espermatozoides. Entre las anormalidades que se encontraron en la muestra destacan, flagelo enrollado y la presencia de gota citoplasmática.

\subsubsection{Parámetros de calidad}

Se seleccionaron las muestras seminales con parámetros fisiológicos de acuerdo a los siguientes criterios: $\geq 100 \times 10^{6} \mathrm{spz} / \mathrm{mlde}$ concentración, $<5 \%$ de anormalidades, $\geq 75 \%$ movilidad $y \geq 80 \%$ viabilidad(Jimenez et al. 2002). 


\subsection{Capacitación in vitro}

Se colocaron5 $\times 10^{6}$ espermatozoides en el pozo de una caja de cultivo con medio TALP-HEPES(3.1 mM KCL, $100 \mathrm{mM} \mathrm{NaCl}, 25 \mathrm{mM} \mathrm{NaHCO}, 0.29 \mathrm{mM}$ $\mathrm{NaH}_{2} \mathrm{PO}_{4}, 21.6 \mathrm{mM} \mathrm{NaC} \mathrm{H}_{5} \mathrm{O}_{3}, 10 \mathrm{mM}$ HEPES, $1 \mathrm{mM} \mathrm{C}{ }_{19} \mathrm{H}_{14} \mathrm{O}_{5} \mathrm{~S}$,2.1 mM $\mathrm{CaCl}_{2} .2 \mathrm{H}_{2} \mathrm{O}, 1.5 \mathrm{mM} \mathrm{MgCl}_{2} .6 \mathrm{H}_{2} \mathrm{O}$ ), volumen final1 ml, $\mathrm{pH}$ 7.2. Se suplementó el día de uso con $6 \mathrm{mg} / \mathrm{ml}$ BSA fracción V y $1 \mathrm{mM}$ Piruvato de Sodio, (Bavister et al. 1983)y se incubaron durante cuatro horas a $38{ }^{\circ} \mathrm{C}$, en una atmósfera húmeda, con $5 \%$ de CO2(Jimenez et al. 2002).

\subsection{Congelación}

El eyaculado fue procesado según la técnica de (Westendorf et al. 1975) con algunas modificaciones.Los crioprotectores utilizados, fueron: Glicerol como crioprotector permeable y sacarosa como no permeable.

\subsubsection{Preparación de la muestra}

La muestra concentrada de semen se, se diluyó ( $1: 1$; vol/vol) en medio TALPHEPES (3.1 mMKCL, $100 \mathrm{mMNaCl}, 25 \mathrm{mM} \mathrm{NaHCO}{ }_{3}, 0.29 \mathrm{mM} \mathrm{NaH}_{2} \mathrm{PO}_{4}, 21.6 \mathrm{mM}$ $\mathrm{NaC}_{3} \mathrm{H}_{5} \mathrm{O}_{3}, 10 \mathrm{mM}$ HEPES, $1 \mathrm{mM} \mathrm{C}_{19} \mathrm{H}_{14} \mathrm{O}_{5} \mathrm{~S}, 2.1 \mathrm{mM} \mathrm{CaCl} 2.2 \mathrm{H}_{2} \mathrm{O}, 1.5 \mathrm{mM} \mathrm{MgCl}$. $\left.6 \mathrm{H}_{2} \mathrm{O}\right)$, $\mathrm{pH} 7.2$, atemperado a la temperatura del eyaculado.Se centrifugó por 1 mina89 rpm, se retiró el sobrenadante y el botón se resuspendió en $800 \mu \mathrm{L}$ de medio básico de congelación ( $3 \mathrm{mM} \mathrm{C}_{12} \mathrm{H}_{22} \mathrm{O}_{11}, 23 \mathrm{mM} \mathrm{C}_{6} \mathrm{H}_{8} \mathrm{O}_{7}, 7 \mathrm{mM} \mathrm{C}_{6} \mathrm{H}_{8} \mathrm{O}_{7}$ ) hasta obtener una concentración de $5 \times 10^{6}$ espermatozoides $/ \mathrm{ml}$.

\subsubsection{Curva de enfriamiento}

Después de adicionar el medio, las muestras se colocaron en un recipiente con agua a $23^{\circ} \mathrm{C}$, y se introdujeron en una cámara fría en la cual se realizó el descenso de temperatura aproximadamente 30 minhasta $5^{\circ} \mathrm{C}\left(0.2^{\circ} \mathrm{C} / \mathrm{min}\right)$. 


\subsubsection{Etapa de crioprotector}

Trascurrido el tiempo de enfriamiento, se añadió el crioprotector (glicerol al 7 \%) atemperado a $5^{\circ} \mathrm{C}$, y se continuó con el descenso de temperatura hasta los $3^{\circ}$ $\mathrm{C}$, en un lapso de $7 \mathrm{~min}\left(0.4^{\circ} \mathrm{C} / \mathrm{min}\right)$.

\subsubsection{Empajillado y sellado}

Al llegar a los $3^{\circ} \mathrm{C}$, se procedió a llenar las pajillas de $0.5 \mathrm{ml}$ que se sellaron con alcohol de polivinilo, antes de iniciar la congelación.

\subsubsection{Congelación}

Las pajillas selladas se expusieron a los vapores de nitrógeno líquido $\left(-70{ }^{\circ} \mathrm{C}\right)$ durante $10 \mathrm{~min}\left(4.46^{\circ} \mathrm{C} / \mathrm{min}\right.$ ) (las pajillas se colocaron a $3 \mathrm{~cm}$ de separación del nitrógeno líquido).

Finalizando el tiempo, las pajillas se sumergieron en el nitrógeno $\left(-196{ }^{\circ} \mathrm{C}\right)$ y se almacenaron en el tanque de nitrógeno por 8 días.

\subsubsection{Descongelación}

Las pajillas se descongelaron en un baño de agua circulante a $39{ }^{\circ} \mathrm{C}$ durante 20 seg. Inmediatamente se centrifugaron a $89 \mathrm{rpm} \times 1$ min para retirar el crioprotector, el botón se resuspendió en $500 \mu \mathrm{L}$ de PBS a $38^{\circ} \mathrm{C}$, los tubos se incubaron hasta el momento de realizar las demás pruebas.

\subsubsection{Evaluación espermática después de la descongelación}

Para determinar la calidad espermática post-descongelación se evaluaron 2 parámetros: movilidad y viabilidad. La evaluación de movilidad post-congelación se realizaron al microscopio de campo claro $(10 \mathrm{X})$, colocando una alícuota de $10 \mu \mathrm{L}$ de la muestra del eyaculado sobre un portaobjetos precalentado a $38^{\circ} \mathrm{C}$, la movilidad se evaluó de forma subjetiva después de una semana de permanecer dentro del contenedor a $-196{ }^{\circ} \mathrm{C}$. 
Los espermatozoides descongelados se colocaron en un portaobjetos a $38^{\circ}$ $\mathrm{C}$, mezclando $5 \mu \mathrm{L}$ del eyaculado y $5 \mu \mathrm{L}$ de colorante. Una vez mezclados ambos volúmenes, se deslizó un portaobjetos para extender la muestra sobre todo el portaobjetos. Se contaron 200 espermatozoides bajo el microscopio óptico a $40 \mathrm{X}$ considerando como vivos a los espermatozoides queno permitieron el paso de colorante, observándose en color blanco, mientras que aquellos espermatozoides que no poseen una membrana plasmática integra permitieron el paso del colorante y se tiñeron de rosado.

\subsection{Distribución de GM1en la membrana plasmática del espermatozoide de cerdo}

La distribución de balsas lipídicas en la membrana plasmática de los espermatozoides no capacitados, capacitados y criopreservados, se llevó a cabo por medio del análisis de fluorescencia; se usóCTX-FITCpues se une con una alta afinidad al GM1 que se encuentra acoplado a las balsas lipídicas.

A las muestras de espermatozoides no capacitados $(n=5)$, capacitados $(n=2)$ y descongelados $(n=5)$, se les ajustó la concentración a $5 \times 10^{6} \mathrm{spz} / \mathrm{mly}$ se incubaron en CTX-FITC $(70 \mu \mathrm{g} / \mathrm{ml}$, durante $30 \mathrm{~min})$ a temperatura ambiente en obscuridad. Inmediatamente después, los espermatozoides se fijaron con paraformaldehido al $4 \%$ a temperatura ambiente $\times 10 \mathrm{~min}$. Se realizaron 2 lavados con PBS(750 rpm $\times 4$ min). En un portaobjetos se colocaron $10 \mu \mathrm{L}$ de la muestra y $5 \mu \mathrm{Lde}$ DABCO $(1,4-$ diaza,2,2,2-biciclo-octano) para atenuar el desvanecimiento de la fluorescencia.

Las muestras se analizaron con ayuda delmicroscopio de

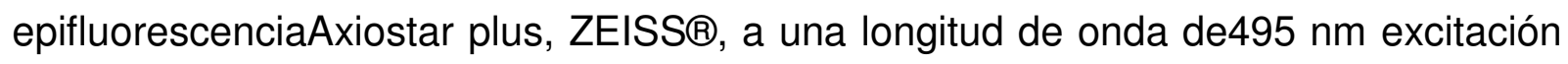
y $525 \mathrm{~nm}$ emisión, a un aumento de 100 X. Para cada tratamiento, se contaron 200 espermatozoides y se analizaron los diferentes patrones de fluorescencia(Colas et al. 2012). 


\subsection{Cuantificación de colesterol.}

El colesterol se midió con elmétodo fluorimétrico, kit Amplex ${ }^{\circledR}$ Red. Los esteres de colesterol se oxidan por acción de la enzima colesterol esterasa, produciendo peróxido de hidrógeno $\left(\mathrm{H}_{2} \mathrm{O}_{2}\right)$ y el producto de cetona correspondiente. El $\mathrm{H}_{2} \mathrm{O}_{2}$ es detectado por la 10-acetil-3,7-dihidroxfenoxazine (reactivo Amplex Red). En presencia de la peroxidasa de rábano picante (HRP), el reactivo Amplex Red reaccionaestequiométricamente $1: 1$ con $\mathrm{elH}_{2} \mathrm{O}_{2}$, produciendoresorufina altamente fluorescente, que tiene un máximo de excitación a 563 nm y máximo de emisión a $587 \mathrm{~nm}$.La preparación de soluciones y metodología se realizaron de acuerdo con las especificaciones del fabricante.Se realizó una curva estándar de colesterolcon concentraciones crecientes de colesterol $(0,2,4,6,8 \mu \mathrm{g} / \mathrm{ml}) \mathrm{n}=3$, con una $R^{2}=$ 0.9882 (figura4).

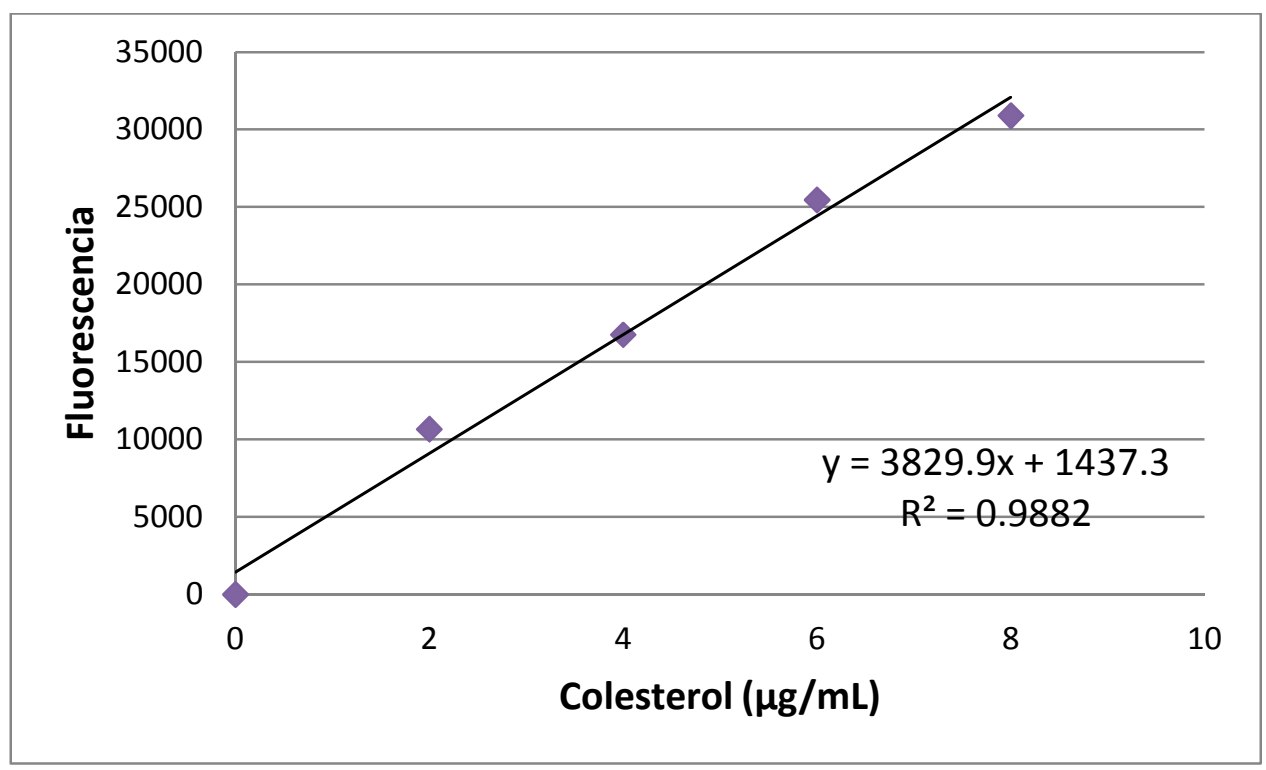

Figura4. Curva estándar de colesterol

\subsubsection{Preparación de la muestra}

Las muestras de espermatozoides no capacitados, capacitados y descongelados se lavaron a $750 \mathrm{rpm} \times 4 \mathrm{~min}$, separando el paquete espermático del 
sobrenadante (plasma seminal, medio de capacitación y medio de criopreservación). El paquete espermático se diluyó en medio amortiguador de trabajo $1 \mathrm{X}$ (0.5 M fosfato de potasio $\mathrm{pH} 7.4,0.25 \mathrm{M} \mathrm{NaCl}, 25 \mathrm{mM}$ ácido clorhídrico, $0.5 \%$ Tritón X-100) ajustando su concentración a $5 \times 10^{6}$ espermatozoides/mly los sobrenadantes se diluyeron 1:100.

En una microplacade 96 pozos secolocaron $50 \mu \mathrm{L}$ de las muestras deespermatozoides, sobrenadante, control positivo $\left(10 \mu \mathrm{MH}_{2} \mathrm{O}_{2}\right)$, control negativo (amortiguador de trabajo $1 \mathrm{X}$ ) y la curva estándar, por triplicado. A cada pozo se le colocaron $50 \mu \mathrm{L}$ del reactivo $300 \mu$ MAmplex Red (2 U/mILHRP,2 U/ml colesterol oxidasa, y $0.2 \mathrm{U} / \mathrm{ml}$ colesterol esterasa, diluido en amortiguadorde trabajo). Las muestras se incubaron por $1 \mathrm{~h}$ a $37^{\circ} \mathrm{C}$, en obscuridad.La fluorescencia se determinó con ayuda de un espectrofluorímetroDTX 880 multimodal detector, a una longitud de onda de 530-560 nm excitación y $590 \mathrm{~nm}$ de emisión. A partir de los valores de fluorescencia obtenida, se calcularon los datos finales de concentración de colesterol en $\mu \mathrm{g} / \mathrm{ml}$, extrapolándolos en la curva estándar de colesterol.

\subsubsection{ANÁLISISESTADÍSTICO}

Se calcularon las medias de las mediciones y se obtuvo su desviación estándar. Para comparar las medias de los valores de cuantificación de colesterol, se realizó una prueba de Kruskal-Wallis, método no paramétrico para probar si un grupo de datos proviene de la misma población. Para los patrones de fluorescencia se utilizó la prueba " $U$ " de Mann-Withney, prueba no paramétrica aplicada a dos muestras independientes. 


\section{RESULTADOS}

\subsection{Evaluación espermática}

Se obtuvieron eyaculados de cerdoLandrace-York, que en promedio presentaron:concentración: $170 \times 10{ }^{6} \pm 8.95 \times 10^{6}$ espermatozoides $/ \mathrm{ml}$; movilidad 85 $\pm 3.54 \%$; viabilidad $93.2 \pm 5.97 \%$ y $3 \pm 1.30$ de anormalidades morfológicas $(n=5)$.

\subsection{Evaluación}

espermática

de muestrascongeladas/descongeladas.

En el presente trabajo se observó una disminución de la movilidad y viabilidad con respecto a los datos que se obtuvieron antes de la congelación.

Las muestras al ser descongeladas presentaron los promedios de $13 \pm 6 \%$ viabilidad y $31 \pm 7 \%$ movilidad.

\subsection{Distribución del GM1 en la membrana del espermatozoide de cerdo.}

Con el fin de poder determinar la distribución del GM1 acoplados a las balsas lipídicas de la membrana plasmática de espermatozoides no capacitados, capacitados y descongelados, se marcaron con CTX-FITCdurante $1 \mathrm{~h}$.

Al analizar las muestras de espermatozoides, se determinaron diferentes patrones de distribución de la fluorescencia, los cuales se clasificaron de acuerdo a la región donde predominó la fluorescencia: 
Patrón A: espermatozoides con distribución de fluorescencia en la región del flagelo y cabeza.

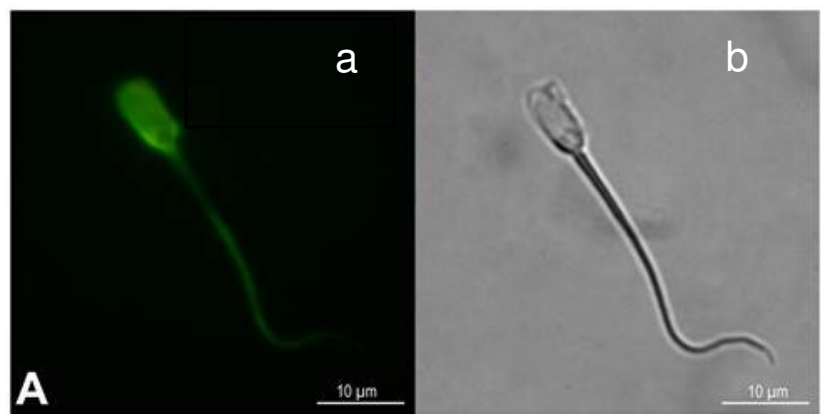

Figura 5. Espermatozoide de cerdo a 100 X con patrón de fluorescencia CTX-FITC (a), en campo claro(b).

Patrón B: espermatozoides con distribución de fluorescencia intensa en la región de la cabeza y débil en el flagelo.

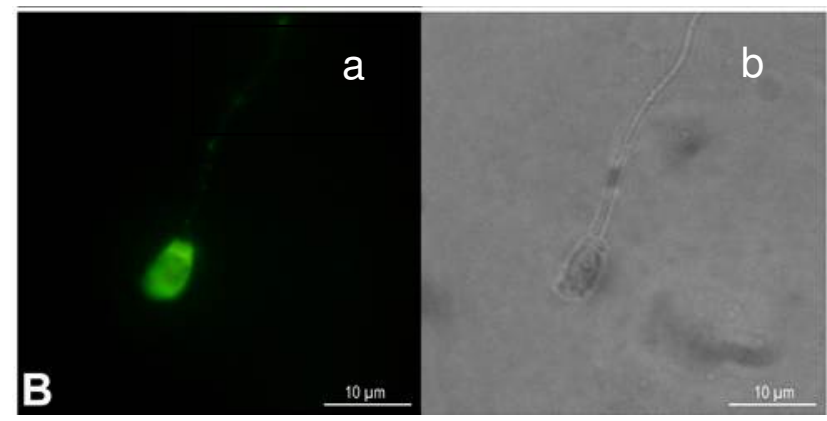

Figura 6. Espermatozoide de cerdo a 100 X con patrón de fluorescencia CTX-FITC (a), en campo claro (b).

Patrón B1: espermatozoides con distribución de la fluorescencia en la región apical y post-acrosomal, con un anillo semicircular que marca el límite anterior del segmento ecuatorial, en la cabeza y una débil fluorescencia en el flagelo.

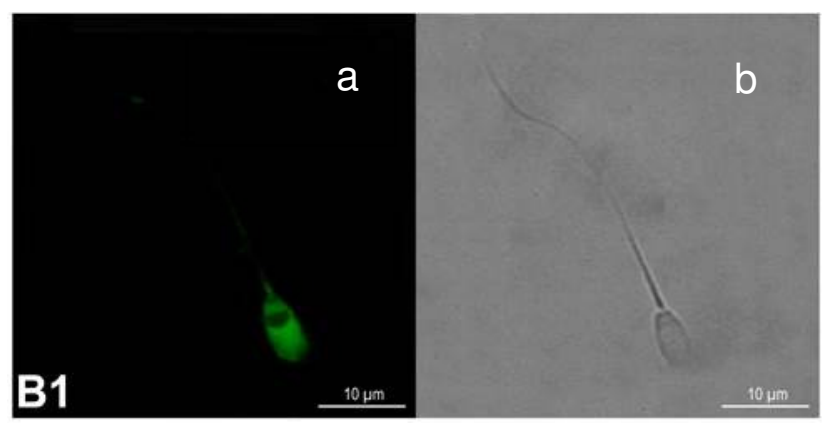

Figura 7. Espermatozoide de cerdo a 100 X con patrón de fluorescencia CTX-FITC (a), en campo claro (b). 
Patrón C: espermatozoides que presentaron la distribución de fluorescencia solo en la cabeza.

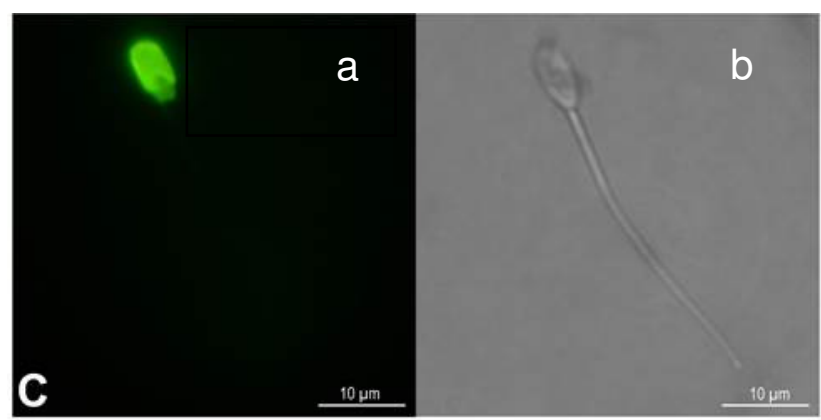

Figura 8.Espermatozoide de cerdo a 100 X con patrón de fluorescencia CTX-FITC (a), en campo claro (b).

Patrón D: distribución de fluorescencia en la región post-acrosomal de la cabeza y pieza media del flagelo.

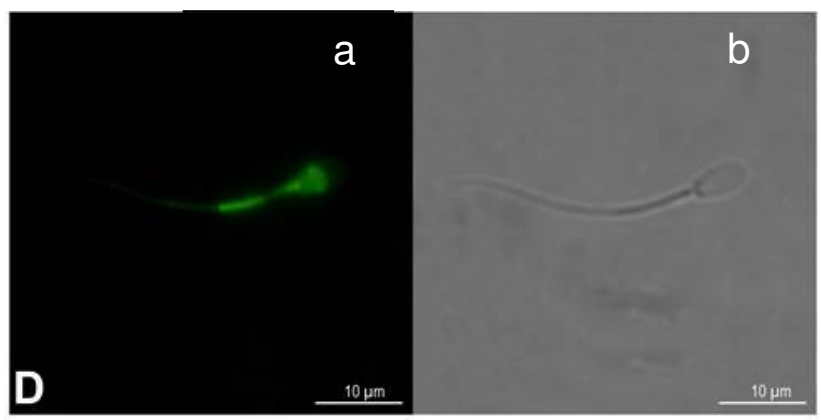

Figura 9. Espermatozoide de cerdo a 100 X con patrón de fluorescencia CTX-FITC (a), en campo claro (b). 
Al realizar el análisis cuantitativo de cada patrón en cada grupo experimental se presentaron los siguientes porcentajes:

Espermatozoides no capacitados que mostraron patrón A,88.7\%; patrón $B, 6.3$ \% y patrón C, $5 \%$. Para los espermatozoides que se sometieron al proceso de capacitación in vitro: patrón A, 5.5 \%; patrón B, 22.7 \% y el patrón C, 71.8 \%. Para los espermatozoides congelados/descongelados, además de los patrones antes mencionados se observaron 2 patrones más (B1 y D) los porcentajes de los patrones fueron: patrón A, 57.8\%; patrón B, $13.9 \%$; patrón B1, 1.7\%; patrón C, 17.1 \% y patrón $\mathrm{D}, 9.5 \%$ (Tabla 1$)$.

Tabla1: Porcentaje de espermatozoides de cerdo de acuerdo a los patrones de fluorescencia con CTX-FITC, NC (no capacitados), C (capacitadosin vitro) y C/D (congelados/descongelados)

\begin{tabular}{|c|c|c|c|}
\hline \hline PATRÓN & NC & C & C/D \\
\hline A & $88.7 \pm 5.9$ & $5.5 \pm 0.2$ & $57.8 \pm 13.1$ \\
\hline B & $6.3 \pm 5.7$ & $22.7 \pm 5.1$ & $13.9 \pm 13.9$ \\
\hline B1 & 0 & 0 & $1.7 \pm 2.7$ \\
\hline C & $5 \pm 6.4$ & $71.8 \pm 5$ & $17.1 \pm 14.5$ \\
\hline D & 0 & 0 & $9.5 \pm 9.5$ \\
\hline
\end{tabular}

Esos datos numéricos fueron obtenidos en dos muestras de modo independiente, no tienen una distribución normal y son muestras pequeñas, por lo que se eligió la prueba $U$ de Mann-Whitney. Es una prueba potente que opera a partir de la sumatoria de los intervalos que presentan los valores de cada grupo una vez que han sido ordenados. Al comparar el patrón de fluorescencia $A$ de espermatozoides no capacitados con el de los descongelados, se encontró que hay diferencia estadísticamente significativa $(p<0.005)$; no se observaron diferencias significativas para los patrones $B(p=0.210)$ y $C(p=0.111)$. 


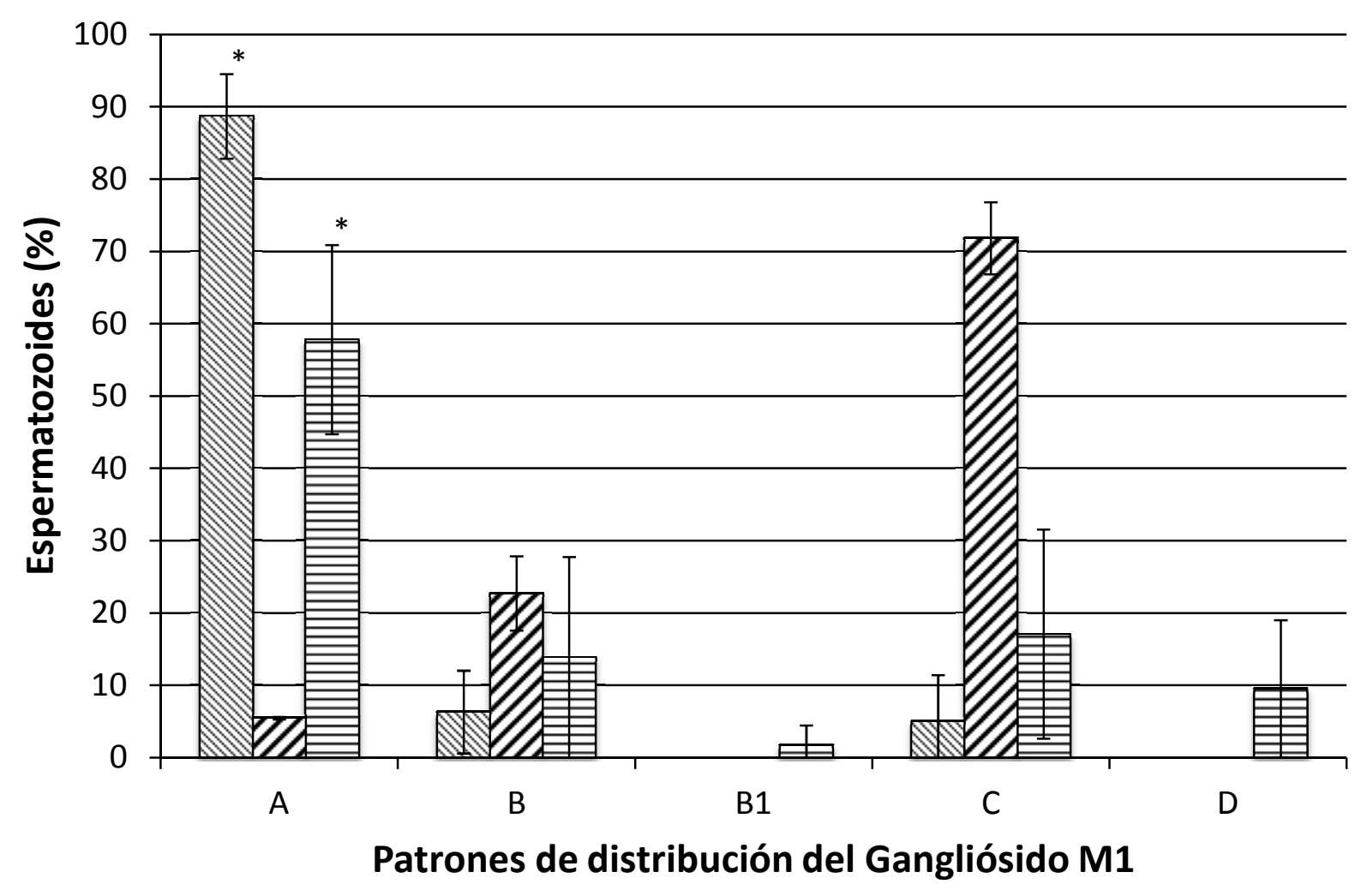

\& No capacitados $\square$ Capacitados $\quad$ Criopreservados

Figura 10: Patrones de distribución de fluorescencia en espermatozoides no capacitados, capacitados y descongelados. A: Flagelo y cabeza, B: Intensa en la cabeza pero débil en el flagelo, B1: Intensa en la cabeza destacando un anillo semicircular y débil en el flagelo, C: en la región de la cabeza y D: en la región post-acrosomal de la cabeza y pieza intermedia del flagelo.El asterisco indica que hay diferencias estadísticamente significativas $p<0.005$

\subsubsection{Cuantificación de colesterol}

Después de realizar el análisis cuantitativo del colesterol de las muestras de espermatozoides y su sobrenadante, se obtuvieron los siguientes promedios Figura 11. En los espermatozoides no capacitados $183.6 \pm 15.2 \mu \mathrm{g} / \mathrm{mly}$ en el plasma seminal $140.6 \pm 53.9 \mu \mathrm{g} / \mathrm{ml}$. En el grupo de espermatozoides capacitados se encontró una mayor concentración de colesterol en el medio de capacitación (349.5 $\pm 25.3 \mu \mathrm{g} / \mathrm{ml}$ ) respecto a la concentración encontrada en los espermatozoides (147.6 $\pm 9.6 \mu \mathrm{g} / \mathrm{ml})$. 
En el grupo de espermatozoides descongelados, los niveles de colesterol no fueron detectados en los espermatozoides, en contraste, se encontró una concentración de colesterol bastante elevada en el medio de congelación (487.9 $\pm 12.5 \mu \mathrm{g} / \mathrm{ml}$ ) Tabla 2 .

Tabla 2: Porcentaje de Concentración de colesterol en espermatozoides de cerdo y sobrenadante

\begin{tabular}{|c|c||c|c||c|c||}
\hline \multicolumn{2}{|c|}{ No capacitados } & \multicolumn{2}{c|}{ Capacitados } & \multicolumn{2}{c|}{ Criopreservados } \\
\hline \hline \multirow{2}{*}{ Espermatozoides } & $\begin{array}{c}\text { Plasma } \\
\text { Seminal }\end{array}$ & Espermatozoides & $\begin{array}{c}\text { Medio } \\
\text { Capacitación }\end{array}$ & Espermatozoides & $\begin{array}{c}\text { Medio } \\
\text { Congelación }\end{array}$ \\
\hline \hline $183.6 \pm 15.2$ & $140.6 \pm 53.9$ & $147.6 \pm 9.6$ & $349.5 \pm 25.3$ & 0 & $487.9 \pm 12.5$ \\
\hline
\end{tabular}

Estos datos numéricos obtenidos en 3 o más muestras de modo independiente, no tienen una distribución normal y son muestras pequeñas. Por estas razones, se realizó la prueba estadística Kruskal-Wallis para determinar si su comportamiento es diferente. La prueba es muy potente, opera comparando los intervalos obtenidos por las puntuaciones de cada nivel de tratamiento contrastando si el intervalo medio de los niveles es equiparable. Los resultados de este análisis permiten rechazar la hipótesis nula, por lo que se puede decir que hubo diferencia significativa $(p<0.05)$ en cuanto a la concentración de colesterol en cada condición. 


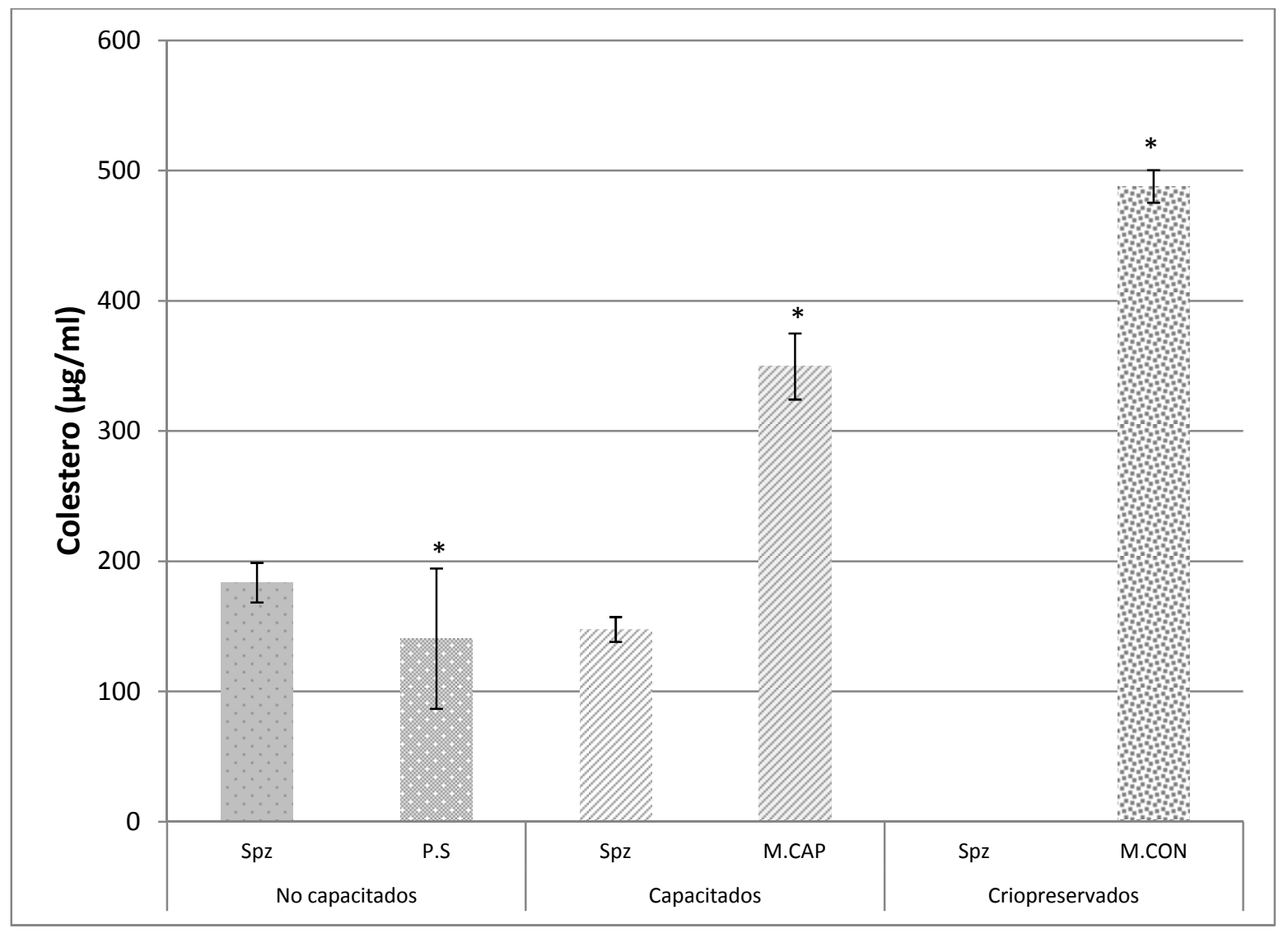

Figura11: Concentración de colesterol $(\mu \mathrm{g} / \mathrm{ml})$ en espermatozoides, No capacitados, capacitados y criopreservados. Spz (espermatozoides), P.S (plasma seminal), M.CAP (medio de capacitación) y M.COM (medio de criopreservación).El asterisco indica que hay diferencias estadísticamente significativas $p<0.005$ 


\section{DISCUSIÓN}

La criopreservación es un proceso que involucra la disminución de la temperatura celular hasta temperaturas no fisiológicas, preservando el potencial y la viabilidad celular. Las técnicas de criopreservación han tenido un éxito aceptable en muchas células eucariotas, no así en los ovocitos ni en los espermatozoides porcinos, en donde se han obtenido tasas bajas de viabilidad post descongelación.

Las balsas lipídicas de los espermatozoides se presentan en regiones bien definidas de la membrana distribuyéndose de manera diferente en las partes del espermatozoide (Flesch et al. 2001). El colesterol es un componente importante de las membranas en general y de las balsas lipídicas en particular, ya que afecta su formación y estabilidad (Simons y Toomre 2000 ). Durante la capacitación, uno de los procesos más importantes es la pérdida de colesterol de la membrana plasmática, lo que aumenta su fluidez y coincide con una relocalización del colesterol en la región apical de la cabeza del espermatozoide (Cross 2004), y posiblemente, también de las balsas. (Shadan et al. 2004).

Los patrones de fluorescencia que presentaron los espermatozoides no capacitados fueron 3 y se les llamó, arbitrariamente, A, B y C. En el patrón A, el GM1 se encontró solo en la región del flagelo y cabeza y se presentó en el 88.7 \% de la población de espermatozoides, el resto, presentó los patrones B y C, estas proporciones coinciden con los reportados por otros autores (Shadan et al. 2004, Bou Khalil et al. 2006), y los han relacionado con la eficiencia de maduración espermática en el epidídimo en cerdo y con el estado de capacitación.

Los espermatozoides se sometieron a capacitación in vitro, después de $4 \mathrm{~h}$ de incubación, el patrón C se presentó en el 71.8 \% de la población, en este patrón, el GM1 se encuentra distribuido en la región de la cabeza de los espermatozoides y se correlaciona con espermatozoides capacitados (Shadan et al. 2004, Bou Khalil et al. 2006), el resto de la población presentó el patrón A y B, en proporciones menores. Estos patrones se han descrito para espermatozoides vivos, donde el gangliósido se 
ha localizado principalmente distribuido en la membrana plasmática del acrosoma y segregado por el anillo sub-acrosomal, por lo que entre los patrones que se encontraron se puede observar un anillo semicircular, patrón B1.(Buttke et al. 2006).El anillo sub-acrosomal funciona como una barrera de difusión, que actúa como una barrera selectiva para determinada clases de lípidos y proteínas específicas, y está relacionado con el citoplasma. (Selvaraj et al. 2006).

Cuando los espermatozoides comienzan a perder la movilidad, el GM1 se distribuye de la membrana del acrosoma, atravesando el anillo sub-acrosomal, a la región post-acrosomal. En el momento que ocurre la muerte celular podría existir una pérdida de interacciones para mantener la barrera. Este patrón se ha encontrado en espermatozoides inmóviles y con anomalías morfológicas, que se ha relacionado con la muerte celular de los espermatozoides (Buttke et al. 2006). El patrón D que predomino en las muestras criopreservadas coincide con estas la descripción antes mencionada.La redistribución del GM1 de la región apical del acrosoma a la región de la membrana post-acrosomal, se puede deber a la interacción entre la membrana interna del acrosoma y la región apical del acrosoma durante la muerte celular del espermatozoides. Aunque aún falta información para entender por completo la redistribución o migración del GM1 a la región post-acrosomal(Selvaraj et al. 2009).

Las diferencias entre los espermatozoides no capacitados y descongelados, respecto alpatrón $A$, fueron significativas $(p<0.005)$ mientras que para los patrones $B$ y $C$ no se observaron. Los patrones de fluorescencia observados muestran que el patrón $\mathrm{A}$ es el que se ve afectado con el proceso de congelación, es decir, la distribución del gangliósido M1 es modificado en gran parte de la membrana de los espermatozoides.Durante la capacitación in vitro, la BSA del medio de incubación colabora con la pérdida de colesterol, lo que inicia el proceso de capacitación espermática y se ha asociado a esto una migración de GM1 hacia la región de la cabeza de los espermatozoides de cerdos (Flesch et al. 2001, Shadan et al. 2004), humanos (Nixon et al. 2011) y carneros (Colas et al. 2012); dicha migración se considera como un indicador de la capacitación espermática en una muestra 
(Shadan et al. 2004, Bou Khalil et al. 2006, Colas et al. 2012). En el grupo de espermatozoides no capacitados, la concentración de colesterol fue de $183.6 \pm 15.2$, siendo la mayor de todas las muestras analizadas. Estos datos nos indican que en la población de espermatozoides, el colesterol se encuentra incluido en la membrana plasmática, el encontrar colesterol en el plasma seminal puede ser indicio de que en algunos espermatozoides está comenzando el proceso llamado falsa capacitación.

Al iniciar la capacitación, los espermatozoides comenzaron a perder colesterol de la membrana plasmática, por lo que se encontró una alta cantidad de colesterol en el medio de los espermatozoides capacitados (349.5 \pm 25.3 ). Nuestros datos confirman los de otros autores que mencionan que la capacitación está relacionada con la pérdida de colesterol de la membrana plasmática (Colas et al. 2012). La liberación de colesterol aumenta considerablemente la fluidez de la membrana, provocando cambios en algunas moléculas, como el GM1, que es desplazado de la región del flagelo a la región de la cabeza. El cambio en la distribución de balsas es indispensable para exponer algunas proteínas que están relacionadas con el reconocimiento ovocito-espermatozoide (Shadan et al. 2004, Jones et al. 2010, Nixon et al. 2011). Del mismo modo que en nuestros resultados, elmovimiento de las balsas lipídicas,asociado con el gangliósidoM1,se incrementó en toda lamembrana de los espermatozoidescriopreservado.

La criopreservaciónparecedañar al espermatozoide, lo que da como resultado un incremento notableen el desordende la membrana, el flujo de colesteroly el porcentajedeespermatozoides capacitados. Estos cambios se ven reflejados en la viabilidad, disminuyendo las funciones de los espermatozoides que sobreviven al proceso de criopreservación, que se refleja en la disminución de la movilidad evaluada. 


\section{CONCLUSIONES}

1. El proceso de criopreservación provocóla migración de las balsas lipídicas hacia la región de la cabeza del espermatozoide criopreservados.

2. El colesterol de la membrana plasmática de los espermatozoides disminuye después de la criopreservación.

\section{PERSPECTIVAS}

1. Determinar la diferencia en movilidad utilizando un sistema computarizado lo que brindaría un análisis más objetivo

2. Evaluar la capacitación y RA mediante ensayos con clorotetraciclina y azul de Coomassie para determinar si la valoración de la posición de las balsas lipídicas realizada mediante el seguimiento del GM1 correlaciona con estos procesos.

3. Cuantificar el colesterol en balsas lipídicas aisladas para determinar cuál es la proporción que se queda anclada a ellas. 


\section{ANEXO}

Medio para capacitar y lavado deespermatozoides para criopreservar TALP-HEPES (Tyrode-Albumina-Lactato-Piruvato-HEPES)

\begin{tabular}{|lc|}
\hline Componente & Concentración mM \\
\hline $\mathbf{K C l}$ & 3.1 \\
\hline $\mathbf{N a C l}$ & 100 \\
\hline $\mathrm{NaHCO}_{3}$ & 25 \\
\hline $\mathrm{NaH}_{2} \mathrm{PO}_{4}$ & 0.29 \\
\hline Lactato de Sodio & 21.6 \\
\hline HEPES & 10 \\
\hline Rojo de Fenol & 1 \\
\hline $\mathbf{C a C l}_{2} \cdot \mathbf{2 H}_{2} \mathbf{O}$ & 2.1 \\
\hline $\mathbf{M g C l}_{2} \cdot 6 \mathrm{H}_{2} \mathbf{O}$ & 1.5 \\
\hline
\end{tabular}

Para el medio de capacitación el medio TALP-HEPES se suplementó con $6 \mathrm{mg} / \mathrm{ml}$ de albumina sérica bovina y $25 \mathrm{mM}$ de piruvato de sodio.

Medio básico de congelación

\begin{tabular}{|lc|}
\hline Componente & Concentración mM \\
\hline Sacarosa & 3 \\
\hline Ácido Cítrico & 23 \\
\hline Tris base & 7 \\
\hline pH & 7.2 \\
\hline
\end{tabular}




\section{BIBLIOGRAFÍA}

Anderson R G (1998). "The caveolae membrane system." Annu Rev Biochem 67: 199-225.

Bailey J L, Lessard C, Jacques J, Breque C, Dobrinski I, Zeng W y Galantino-Homer $H L$ (2008). "Cryopreservation of boar semen and its future importance to the industry." Theriogenology 70(8): 1251-1259.

Bavister B D, Leibfried M L y Lieberman G (1983). "Development of preimplantation embryos of the golden hamster in a defined culture medium." Biol Reprod 28(1): 235-247.

Blank N, Schiller M, Krienke S, Wabnitz G, Ho A D y Lorenz H M (2007). "Cholera toxin binds to lipid rafts but has a limited specificity for ganglioside GM1." Immunol Cell Biol 85(5): 378-382.

Boerke A, Tsai P S, Garcia-Gil N, Brewis I A y Gadella B M (2008). "Capacitationdependent reorganization of microdomains in the apical sperm head plasma membrane: functional relationship with zona binding and the zona-induced acrosome reaction." Theriogenology 70(8): 1188-1196.

Bou Khalil M, Chakrabandhu K, Xu H, Weerachatyanukul W, Buhr M, Berger T, Carmona E, Vuong N, Kumarathasan P, Wong P T, Carrier D y Tanphaichitr N (2006). "Sperm capacitation induces an increase in lipid rafts having zona pellucida binding ability and containing sulfogalactosylglycerolipid." Dev Biol 290(1): 220-235.

Browman D T, Hoegg M B y Robbins S M (2007). "The SPFH domain-containing proteins:more than lipid raft markers. ." Trends Cell Biol 17: 394-402.

Brown D A y Rose J K (1992). "Sorting of GPI-anchored proteins to glycolipidenriched membrane subdomains during transport to the apical cell surface." Cell Biology 68: 533-544.

Buttke D E, Nelson J L, Schlegel P N, Hunnicutt G R y Travis A J (2006). "Visualization of GM1 with cholera toxin B in live epididymal versus ejaculated bull, mouse, and human spermatozoa." Biol Reprod 74(5): 889-895.

Chini B y Parenti M (2004). "G-protein coupled receptors in lipid rafts and caveolae: how,when and why do they go there? ." J Mol Endocrinol 32: 325-338.

Chinnapen D J, Chinnapen H, Saslowsky D y Lencer W I (2007). "Rafting with cholera toxin: endocytosis and trafficking from plasma membrane to ER." FEMS Microbiol Lett 266: 129-137.

Chun M, Liyanage U K, Lisanti M P y Lodish H F (1994). "Signal transduction of a G protein-coupled receptor in caveolae: colocalization of endothelin and its receptor with caveolin." Proc Natl Acad Sci U S A 91: 11728-11732.

Colas C, Perez-Pe R, Casao A, Ollero M, Calleja L, Gallego M, Muiño-B T y CebrianPerez J A (2012). "Remodelling of Lipid Rafts during In vitro Capacitation and Acrosome Reaction of Ram Spermatozoa." Biochem Anal Biochem S5: 2-9. 
Cross N L (2004). "Reorganization of lipid rafts during capacitation of human sperm." Biol Reprod 71(4): 1367-1373.

De Mercado E, Rodriguez A, Gomez E y Sanz E (2010). "Cryopreservation of Iberian pig spermatozoa. Comparison of different freezing extenders based on postthaw sperm quality." Anim Reprod Sci 118(1): 54-61.

Degroote S, Wolthoorn J y van Meer G (2004). "The cell biology of glycosphingolipids." Semin Cell Dev Biol 15(4): 375-387.

Eriksson B M y Rodriguez-Martinez H (2000). "Effect of freezing and thawing rates on the post-thaw viability of boar spermatozoa frozen in FlatPacks and Maxistraws." Anim Reprod Sci 63(3-4): 205-220.

Ernst A M y Brugger B (2013). "Sphingolipids as modulators of membrane proteins." Biochim Biophys Acta, S1388-1981(13)00239-4 [pii]10.1016/j.bbalip.2013.10.016.

Flesch F, Brouwers J, Nievelstein P, Verkleij A, Van Golde L, Colenbrander B y Gadella B (2001). " Bicarbonate stimulated phospholipid scrambling induces cholesterol redistribution and enables cholesterol depletion in the sperm plasma membrane." J Cell Sci 114: 3543-3555.

Flores E, Fernandez-Novell J M, Pena A y Rodriguez-Gil J E (2009). "The degree of resistance to freezing-thawing is related to specific changes in the structures of motile sperm subpopulations and mitochondrial activity in boar spermatozoa." Theriogenology 72(6): 784-797.

Gadella B M, Tsai P S, Boerke A y Brewis I A (2008). "Sperm head membrane reorganisation during capacitation." Int J Dev Biol 52(5-6): 473-480.

Grossfeld R, Sieg B, Struckmann C, Frenzel A, Maxwell W M y Rath D (2008). "New aspects of boar semen freezing strategies." Theriogenology 70(8): 1225-1233.

Gustavsson J, Parpal S, Karlsson M, Ramsing C, Thorn H, Borg M, Lindroth M, Peterson K H, Magnusson K E y Stralfors P (1999). "Localization of the insulin receptor in caveolae of adipocyte plasma membrane." Faseb J 13: 1961-1971.

Helms J B y Zurzolo C (2004). "Lipids as targeting signals: lipid rafts and intracellular trafficking." Traffic 5(4): 247-254.

Hernandez M, Roca J, Calvete J J, Sanz L, Muino-Blanco T, Cebrian-Perez J A, Vazquez J M y Martinez E A (2007). "Cryosurvival and in vitro fertilizing capacity postthaw is improved when boar spermatozoa are frozen in the presence of seminal plasma from good freezer boars." J Androl 28(5): 689-697.

Holt W V, Medrano A, Thurston L M y Watson P F (2005). "The significance of cooling rates and animal variability for boar sperm cryopreservation: insights from the cryomicroscope." Theriogenology 63(2): 370-382.

Jimenez I, Gonzalez-Marquez H, Ortiz R, Betancourt M, Herrera J y Fierro R (2002). "Expression of lectin receptors on the membrane surface of sperm of fertile and subfertile boars by flow cytometry." Arch Androl 48(2): 159-166.

Jones R, Howes E, Dunne P D, James P, Bruckbauer A y Klenerman D (2010). "Tracking diffusion of GM1 gangliosides and zona pellucida binding molecules in 
sperm plasma membranes following cholesterol efflux." Dev Biol 339(2): 398406.

Kalka D, von Reitzenstein C, Kopitz J y Cantz M (2001). "The plasma membrane ganglioside sialidase cofractionates with markers of lipid rafts." Biochem Biophys Res Commun 283(4): 989-993.

Kovbasnjuk O, Edidin M y Donowitz M (2001). "Role of lipid rafts in Shiga toxin interaction with the apical surface of Caco-2 cells." J Cell Sci 114: 4025-4031.

Maxwell W M y Johnson L A (1999). "Physiology of spermatozoa at high dilution rates: the influence of seminal plasma." Theriogenology 52(8): 1353-1362.

Miranda P V, Allaire A, Sosnik J y Visconti P E (2009). "Localization of low-density detergent-resistant membrane proteins in intact and acrosome-reacted mouse sperm." Biol Reprod 80(5): 897-904.

Monier S, Parton R G, Vogel F, Behlke J, Henske A y Kurzchalia T V (1995). "VIP21caveolin, a membrane protein constituent of the caveolar coat, oligomerizes in vivo and in vitro." Mol Biol Cell 6(7): 911-927.

Mouritsen O G y Zuckermann M J (2004). "What's so special about cholesterol?" Lipids 39(11): 1101-1113.

Munro S (2003). " Lipid rafts: elusive or illusive?" Cell 115: 377-388.

Murata M, Peranen J, Schreiner R, Wieland F, Kurzchalia T V y Simons K (1995). "VIP21/caveolin is a cholesterol-binding protein." Proc Natl Acad Sci U S A 92(22): 10339-10343.

Naz R K y Rajesh P B (2004). "Role of tyrosine phosphorylation in sperm capacitation / acrosome reaction." Reprod Biol Endocrinol 2: 75.

Nelson W J y Rodriguez-Boulan E (2004). "Unravelling protein sorting." Nat Cell Biol 6(4): 282-284.

Nixon B, Mitchell L A, Anderson A L, McLaughlin E A, O'Bryan M K y Aitken R J (2011). "Proteomic and functional analysis of human sperm detergent resistant membranes." J Cell Physiol 226(10): 2651-2665.

Ostrom R S, Bundey R A y Insel P A (2004). "Nitric oxide inhibition of adenylyl cyclase type 6 activity is dependent upon lipid rafts and caveolin signaling complexes." J Biol Chem 279(19): 19846-19853.

Pike $L$ (2006). "Rafts defined: a report on the keystone symposium on lipid rafts and cell function." J Lipid Res 47:1597-1598.

Pike L J (2004). "Lipid rafts: heterogeneity on the high seas." Biochem J 378: 281292.

Prinetti A, Loberto N, Chigorno V y Sonnino S (2009). "Glycosphingolipid behaviour in complex membranes." Biochim Biophys Acta 1788(1): 184-193.

Sancho S, Casas I, Ekwall H, Saravia F, Rodriguez-Martinez H, Rodriguez-Gil J E, Flores E, Pinart E, Briz M, Garcia-Gil N, Bassols J, Pruneda A, Bussalleu E, Yeste M y Bonet $S$ (2007). "Effects of cryopreservation on semen quality and 
the expression of sperm membrane hexose transporters in the spermatozoa of Iberian pigs." Reproduction 134(1): 111-121.

Scheiffele P, Verkade P, Fra A M, Virta H, Simons K y Ikonen E (1998). "Caveolin-1 and -2 in the exocytic pathway of MDCK cells." J Cell Biol 140(4): 795-806.

Selvaraj V, Asano A, Buttke D E, McElwee J L, Nelson J L, Wolff C A, Merdiushev T, Fornes M W, Cohen A W, Lisanti M P, Rothblat G H, Kopf G S y Travis A J (2006). "Segregation of micron-scale membrane sub-domains in live murine sperm." J Cell Physiol 206(3): 636-646.

Selvaraj V, Asano A, Buttke D E, Sengupta P, Weiss R S y Travis A J (2009). "Mechanisms underlying the micron-scale segregation of sterols and GM1 in live mammalian sperm." J Cell Physiol 218(3): 522-536.

Shadan S, James P S, Howes E A y Jones R (2004). "Cholesterol efflux alters lipid raft stability and distribution during capacitation of boar spermatozoa." Biol Reprod 71(1): 253-265.

Simons K y Ehehalt R (2002). "Cholesterol, lipid rafts, and disease." J Clin Invest 110(5): 597-603.

Simons K y lkonen E (1997). "Functional rafts in cell membranes." Nature 387: 569572.

Simons K y Ikonen E (2000). "How cells handle cholesterol." Science 290(5497): 1721-1726.

Simons K y Toomre D (2000). "Lipid rafts and signal transduction." Nat Rev Mol Cell Biol. 1(1): 31-39.

Simons K y Van Meer G (1988). "Lipid sorting in epithelial cells." Biochemistry 27: 6197-6202.

Singer S J y Nicolson G L (1972). "The fluid mosaic model of the structure of cell membranes." Science 175(4023): 720-731.

Sonnino S y Prinetti A (2009). "Sphingolipids and membrane environments for caveolin." FEBS Lett 583(4): 597-606.

Sonnino S y Prinetti A (2013). "Membrane domains and the "lipid raft" concept." Curr Med Chem 20(1):4-21.

Stan R V (2005). "Structure of caveolae. ." Biochim Biophys Acta 1746: 334-348.

Suomalainen M (2002). "Lipid rafts and assembly of enveloped viruses." Traffic 3: 705-709.

Vadnaisa M L y Althousea G C (2011). "Characterization of capacitation, cryoinjury, and the role of seminal plasma in porcine sperm." Theriogenology 76 15081516.

Van G, Voelker DR y GW F (2008). "Membrane lipids: where are they a how they behave." Nature reviews in molecular cell biology 9(112-124).

Visconti $P$ (2009). "Understanding the molecular basis of sperm capacitation through kinase design." Proc Natl Acad Sci U S A. 20;106(3): 667-668. 
Visconti P E, Krapf D, de la Vega-Beltran J L, Acevedo J J y Darszon A (2011). "Ion channels, phosphorylation and mammalian sperm capacitation." Asian $\mathrm{J}$ Androl 13(3): 395-405.

Waterhouse K E, Hofmo P O, Tverdal A y Miller R R, Jr. (2006). "Within and between breed differences in freezing tolerance and plasma membrane fatty acid composition of boar sperm." Reproduction 131(5): 887-894.

Westendorf P, Richter L y Treu H (1975). "[Deep freezing of boar sperma. Laboratory and insemination results using the Hulsenberger paillete method]." Dtsch Tierarztl Wochenschr 82(7): 261-267.

Zajchowski L D y Robbins S M (2002). "Lipid rafts and little caves. Compartmentalized signalling in membrane microdomains." Eur $\mathrm{J}$ Biochem 269(3): 737-752. 